Research Article

\title{
Effect of the Preexisting Fissure with Different Fillings in PMMA on Blast-Induced Crack Propagation
}

\author{
Xin Yang, ${ }^{1}$ Xiangguo Zeng $\mathbb{D}^{1},{ }^{1}$ Chuanjin Pu $\mathbb{D},{ }^{2,3}$ and Dingjun Xiao ${ }^{2,3}$ \\ ${ }^{1}$ College of Architecture and Environment, Sichuan University, Chengdu, Sichuan 610065, China \\ ${ }^{2}$ School of Environment and Resource, Southwest University of Science and Technology, Mianyang, Sichuan 621010, China \\ ${ }^{3}$ Shock and Vibration of Engineering Materials and Structures Key Laboratory of Sichuan Province, Mianyang, \\ Sichuan 621000, China \\ Correspondence should be addressed to Xiangguo Zeng; xiangguozeng@scu.edu.cn and Chuanjin Pu; puchuanjin@sina.com
}

Received 22 October 2017; Accepted 8 May 2018; Published 8 July 2018

Academic Editor: Pavel Lejcek

Copyright (C) 2018 Xin Yang et al. This is an open access article distributed under the Creative Commons Attribution License, which permits unrestricted use, distribution, and reproduction in any medium, provided the original work is properly cited.

\begin{abstract}
In order to study the dynamic crack propagation law in fissured rock under the different fillings, a borehole with $7 \mathrm{~mm}$ diameter was processed in the center of a polymethyl methacrylate (PMMA) specimen. The preexisting fissure with different angles $\left(\theta=0^{\circ}\right.$, $45^{\circ}$, and $\left.90^{\circ}\right)$ and different distances $(L=20,30,40,50$, and $60 \mathrm{~mm})$ was prefabricated around the borehole. Air, soil, and water were employed as fillings in the fissure, respectively. The experiment of explosive loading was carried out by a single detonator, and the dynamic crack propagation process of the experimental specimens was simulated by nonlinear dynamics software AUTODYN. The results show that the blast-induced cracks are the most favorable and unfavorable to propagate when $\theta=0^{\circ}$ and $\theta=45^{\circ}$, respectively. The length of the far-end wing crack decreases with the increase of the distance $L$, and the length of the far-end wing crack in the air-filled specimens is larger than those in soil-filled and water-filled specimens. The damage-pressure curve of the far-end wing crack initiation point shows "S"-type change, and the damage-pressure curve shows two obvious damage evolution processes of initial nonlinear and later linear stages. With the increase of the angle, the distance from the borehole to the crack initiation point decreases and the compressive stress wave peak value should increase, but the tensile force peak value decreases. Meanwhile, the relationships between pressure and average velocity of the initiation point and $L, \theta$, and fillings are established, respectively. The numerical simulation agrees with the experimental results well. It can be seen that the fillings types, angle, and distance have a mutual restraint relationship with the reflected and absorbed stress wave energy. The phenomenon of crack propagation under different fillings can be explained well from the viewpoint of discontinuity degree and stress wave energy, which reveals the general law of blast-induced crack propagation.
\end{abstract}

\section{Introduction}

A large number of randomly distributed joints and fissures make the rock mass to show properties of the discontinuity, anisotropy, and inhomogeneity. For the fissured rock, when the stress waves travel to the fissure surface, the stress waves can produce the phenomena of reflection, refraction, diffraction, and transmission [1-3], which will influence the propagation direction and length of blast-induced cracks. Meanwhile, the loss of explosive gas in fissures causes the rock mass far away from borehole to decrease significantly in the explosive energy utilization rate, which will reduce the scope and effect of the blasting fragmentation, and not only affect the contour shape of the tunnel or mining slope and increase the explosive consumption greatly but also produce unfavorable effects on safety of construction, support, and postoperation, and so on as well as ultimately result in lowering production efficiency and increasing production cost.

Song and Kim [4] analyzed the mechanical properties of crack initiation, propagation, and bifurcation in the explosion process of rock fracture by numerical simulation. Zhu et al. [5-7] used AUTODYN to simulate the blast-induced crack propagation and concluded that the fissure hindered crack propagation seriously and fissure width and fillings also have an important influence on crack propagation. Ma et al. [8] 
also utilized LS-DYNA to simulate the crack propagation in fissured rock mass and obtained the rule that the fissure greatly impeded crack propagation as well and the rock near the fissure or free side was more seriously broken caused by the reflected tensile stress waves [9]. Wang and Konietzky [10] analyzed the dynamic fracture process of the fissured rock mass in combination with LS-DYNA and UDEC and concluded that different fissure types could cause different crack propagation laws. Sharafisafa et al. [11] studied the effect of fissure types on blast-induced crack propagation and concluded that the horizontal fissure was more favorable for crack propagation than inclined and vertical fissures. $\mathrm{Wu}$ and Wong [12] investigated initiation stress, initiation angle, and propagation law of wing crack caused by preexisting fissure end at different angles under uniaxial compression by using the numerical method. Li and Wong [13] revealed that the preexisting fissures of different angles had an important effect on wing crack initiation position, propagation angles, and propagation priority by AUTODYN. Zhuang et al. [14] researched the difference of wing crack propagation law between unfilled and filled preexisting fissures in rock-like brittle materials under uniaxial compression in the crack initiation stress and initiation angle. Yang et al. [15] studied the crack propagation when explosion stress waves with oblique incidence propagate to preexisting fissures and considered the propagation law of wing crack had an important relationship with initial compressive stress. Hu et al. [16] and Yang et al. [17, 18] both researched blast-induced crack propagation when stress wave traveled to preexisting fissure at different incident angles in PMMA and concluded the different angles would cause the different propagation mechanism of the far-end wing crack.

Although many researchers have studied largely the blast-induced crack propagation law in fissured rock mass, they mostly studied the influence of single variable on crack propagation, such as stress wave incident angles $[14,16,17]$ and fillings [5]. So they lack to consider synthetically the influence of filling material types and the angle and distance of fissure to borehole on the blast-induced crack propagation. Firstly, this paper mainly studies the influence of the preexisting fissure with the different filling materials (air, soil, and water) on the blast-induced crack propagation and the crack propagation law at the end of preexisting fissure by experimental studies, and then, the crack propagation law in the experiment will be further revealed by the corresponding numerical simulation through AUTODYN. The research of this paper is conducive to improving the energy utilization efficiency of rock blasting and the effect of rock fragmentation and the safety level of fissured rock slope and tunnel, which can provide theoretical basis for improving blasting design and optimizing blasting parameters.

\section{Explosive Experiment}

2.1. Experimental Scheme. PMMA and rock exhibit an anisotropic behavior and brittle characteristic under explosive loading $[19,20]$, and thus, PMMA is chosen as an experimental material in our study. With a length $400 \mathrm{~mm} \times$ width $400 \mathrm{~mm} \times$ height $5 \mathrm{~mm}$ of the PMMA plate

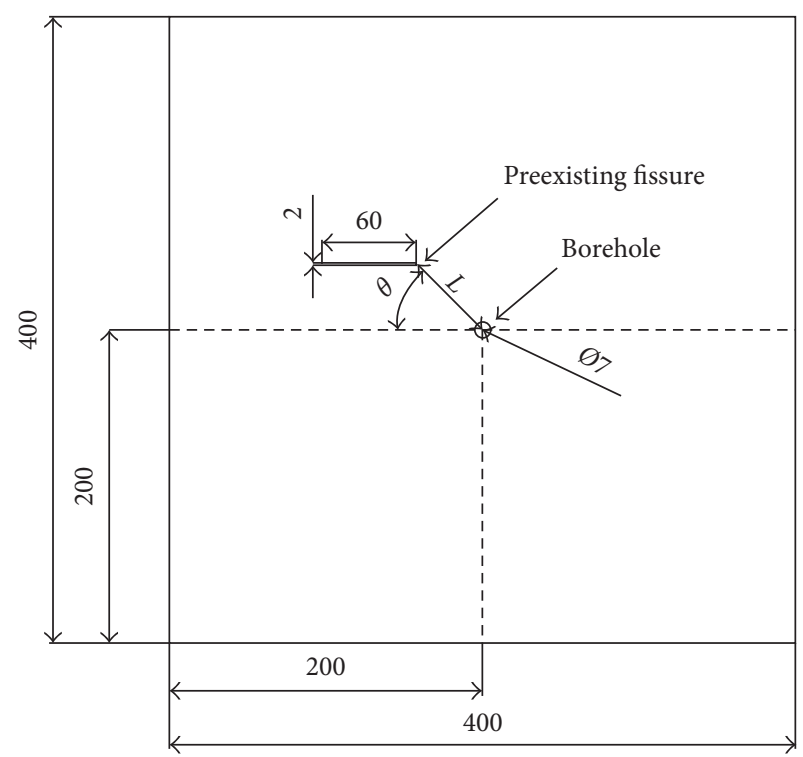

Figure 1: PMMA specimen (unit: mm).

Table 1: The variables of the specimens.

\begin{tabular}{lcccccc}
\hline Fillings & $\theta\left(^{\circ}\right)$ & \multicolumn{5}{c}{$L(\mathrm{~mm})$} \\
\hline \multirow{3}{*}{ Air/soil/water } & 0 & 20 & 30 & 40 & 50 & 60 \\
& 45 & 20 & 30 & 40 & 50 & 60 \\
& 90 & 20 & 30 & 40 & 50 & 60 \\
\hline
\end{tabular}

as the experimental specimen, a $7 \mathrm{~mm}$ diameter hole is located in the center of the specimen, and the preexisting fissure size is length $60 \mathrm{~mm} \times$ width $2 \mathrm{~mm} \times$ height $5 \mathrm{~mm}$, as shown in Figure 1. $\theta$ is the angle between the line from the borehole center to the proximal end of preexisting fissure and axis in the longitudinal direction of the preexisting fissure, and $\theta$ is called the angle between borehole and preexisting fissure for short, $L$ is the distance from the borehole center to the proximal end of preexisting fissure. According to the fillings types, experiments are divided into three groups, namely, air group, soil group, and water group; each group is divided into three subgroups with $\theta$ as variable, namely, $0^{\circ}$ subgroup, $45^{\circ}$ subgroup, and $90^{\circ}$ subgroup; each subgroup has five PMMA specimens with $L$ as variable, and $L$ is $20,30,40,50$, and $60 \mathrm{~mm}$, respectively, as shown in Table 1.

2.2. Experimental Procedures. The experimental procedures are as follows:

(i) The laser lathe was applied to incise the PMMA specimen and prefabricate the borehole and preexisting fissure, which requires walls of the borehole and preexisting fissure to be smooth and perpendicular to the specimen surface; Sellotape was pasted tightly on the backside of preexisting fissure in each soil-filled specimen and water-filled specimen; gaskets were used to form a holder for underlaying the specimen via its four corners to the same height on the ground, which aimed at preventing the 
(1) $0^{\circ}$

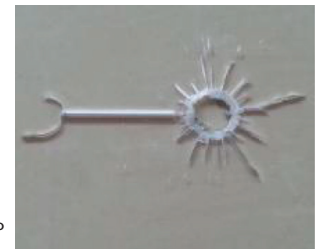

$$
L=20 \mathrm{~mm}
$$

(2) $45^{\circ}$

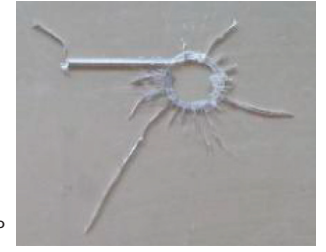

$L=20 \mathrm{~mm}$

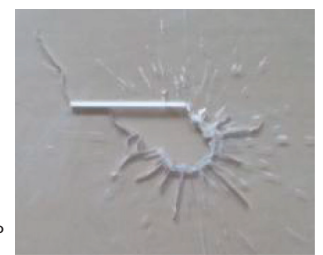

$L=20 \mathrm{~mm}$

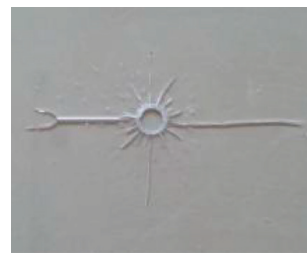

$L=30 \mathrm{~mm}$

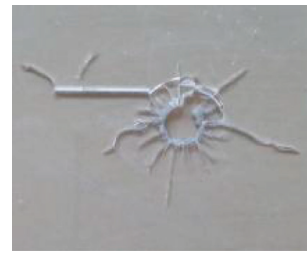

$L=30 \mathrm{~mm}$

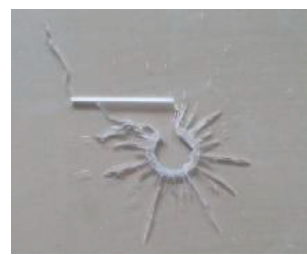

$L=30 \mathrm{~mm}$

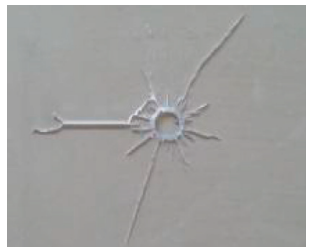

$L=40 \mathrm{~mm}$

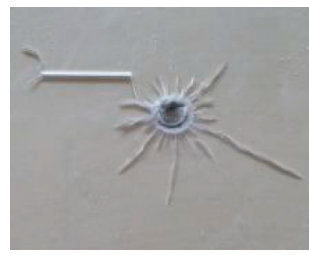

$L=40 \mathrm{~mm}$

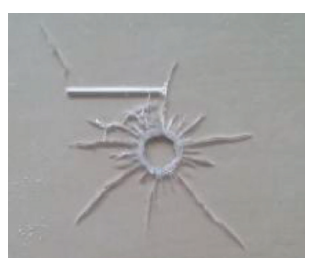

$L=40 \mathrm{~mm}$

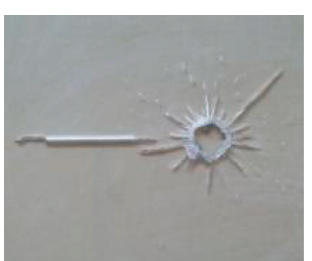

$L=50 \mathrm{~mm}$

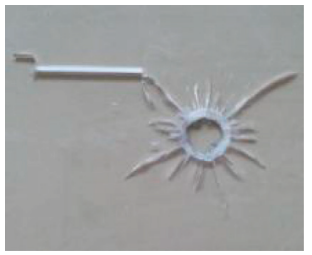

$L=50 \mathrm{~mm}$

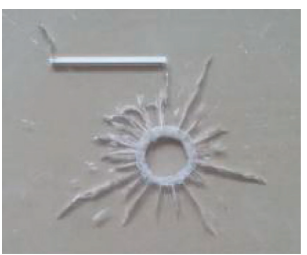

$L=50 \mathrm{~mm}$

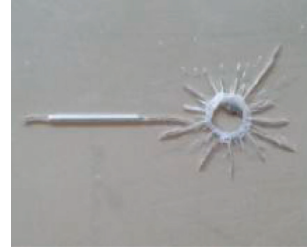

$L=60 \mathrm{~mm}$

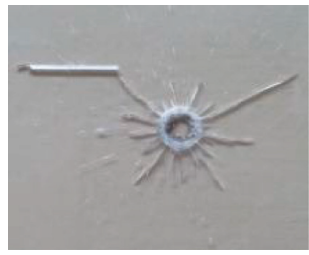

$L=60 \mathrm{~mm}$

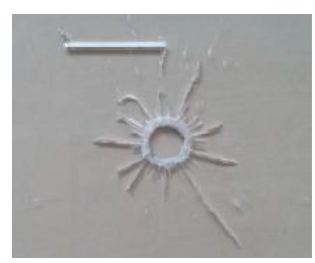

$L=60 \mathrm{~mm}$

FIgURE 2: Air-filled PMMA specimens after explosion.

bottom of the detonator from touching the ground to change the main charge zone position.

(ii) To the air-filled group, (1) a \#8 instantaneous electric detonator was fixed with the same batch, the similar resistance values in the center of the borehole and the detonator must be perpendicular to the specimen surface, and all the main charge zones of the detonator were required to align the thickness of the specimen in the same position; (2) the specimen was put on the holder; (3) a thin wood plate that had a slightly bigger hole than the borehole with the same size of the specimen was covered above the specimen to prevent the detonator debris from scratching in the explosion; and (4) the detonator was initiated, and the specimen was recycled after explosion.

(iii) To the soil-filled group, firstly soil was filled in preexisting fissure completely, which requires soil to be consistent with the thickness of the specimen so that it does not invade into the rear paste area of Sellotape, and then, the steps (1), (2), (3), and (4) were followed in the air-filled group.

(iv) To the water-filled group, firstly the steps (1) and (2) were followed in the air-filled group; then, a syringe was used to fill water in the preexisting fissure completely, and it was ensured that no bubbles exist in the fissure; and lastly, the steps (3) and (4) were followed in the air-filled group.

2.3. Experimental Results and Discussion. The crack propagation effects of the experimental specimens after explosion are shown in Figures 2-4.
2.3.1. The Influence of Fillings, Angle, and Distance on Crack Propagation. The mechanical properties of the fillings affect the discontinuity degree of the specimen, which was measured by the wave impedance. The wave impedances of four media are shown in Table 2 [21-24], where $\rho$ is the density, $c$ is the longitudinal wave velocity, $\eta$ is the wave impedance, and $\Delta \eta$ is the wave impedance difference value. According to the rock wave impedance matching viewpoint [25], the difference value of wave impedance between the PMMA and fillings is inversely proportional to the discontinuity degree of the specimen and is proportional to the magnitude of the blocked energy of stress wave, which means that the bigger the wave impedance difference value, the smaller the discontinuity degree and the more the blocked energy. Compared with wave impedances of PMMA, soil, and water, it can be considered that stress waves are completely blocked in the air-filled specimen because of its minimum wave impedance [26]; soil-filled and water-filled specimens have a bigger discontinuity degree, which is conducive to stress wave travel. For the angle $\theta$ and the distance $L$, it is generally believed that the larger the angle and the smaller the distance of the three kinds of filling specimens, the larger the reflected stress wave energy. But the smaller the distance in the soil-filled and water-filled specimens, the greater the absorbed stress wave energy. It can be seen that the fillings types, angle, and distance have a mutual restraint relationship with the reflected and absorbed stress wave energy. From the experimental results, it is because that the three variables lead to different crack propagation results, and the analysis should also consider the influence of three variables and the mutual restraint relationship of stress wave energy on blastinduced crack propagation so as to make a more comprehensive explanation. 
(1) $0^{\circ}$

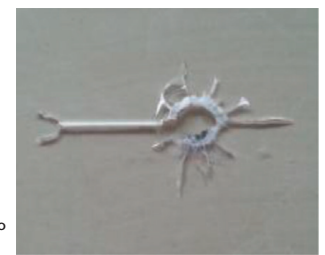

$L=20 \mathrm{~mm}$

(2) $45^{\circ}$

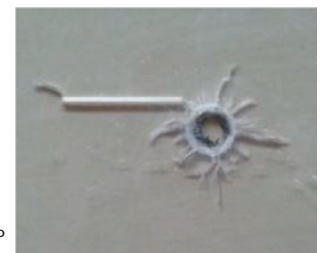

$L=20 \mathrm{~mm}$

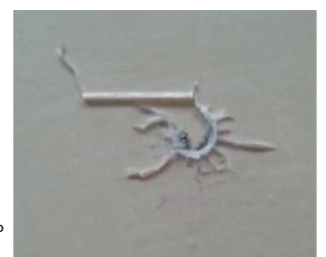

$L=20 \mathrm{~mm}$

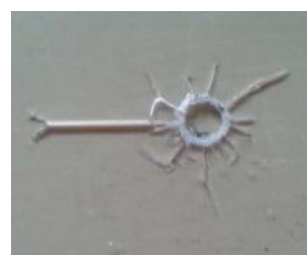

$L=30 \mathrm{~mm}$

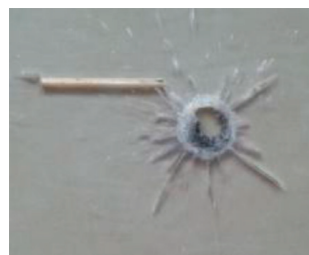

$L=30 \mathrm{~mm}$

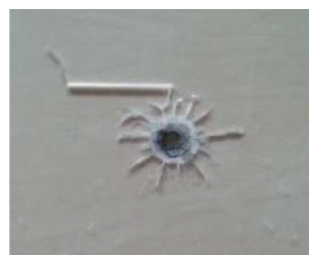

$L=30 \mathrm{~mm}$

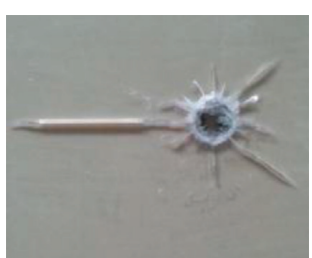

$L=40 \mathrm{~mm}$

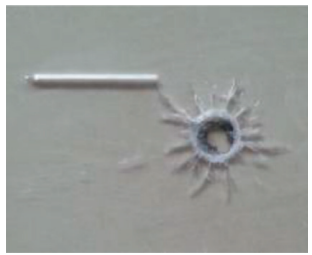

$L=40 \mathrm{~mm}$

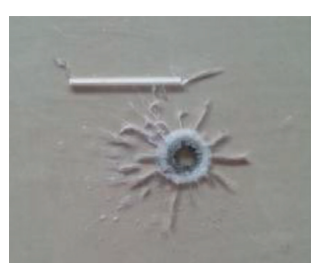

$L=40 \mathrm{~mm}$

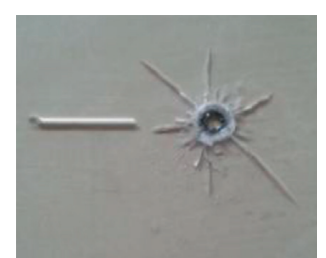

$L=50 \mathrm{~mm}$

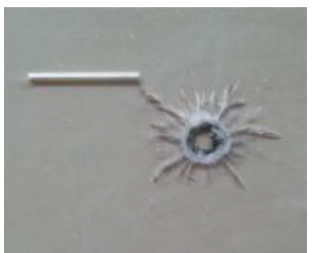

$L=50 \mathrm{~mm}$

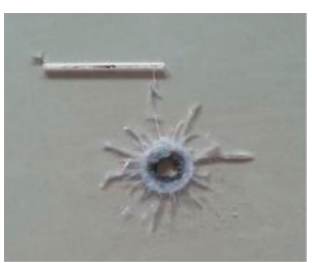

$L=50 \mathrm{~mm}$

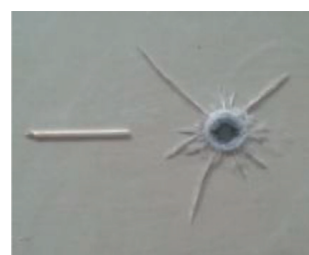

$L=60 \mathrm{~mm}$

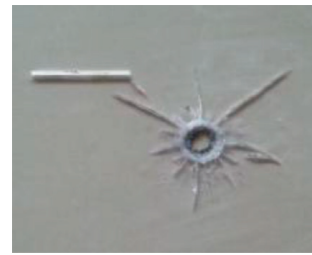

$L=60 \mathrm{~mm}$

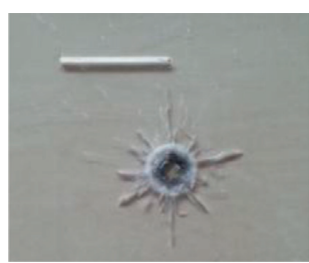

$L=60 \mathrm{~mm}$

FIgURe 3: Soil-filled PMMA specimens after explosion.

(1) $0^{\circ}$

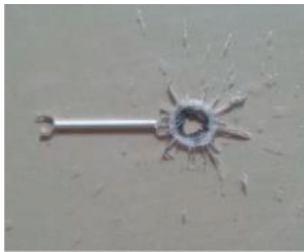

$L=20 \mathrm{~mm}$

(2) $45^{\circ}$

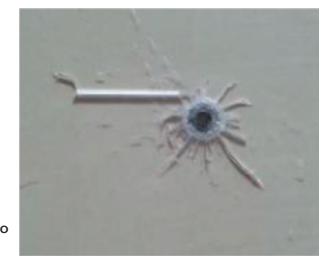

$L=20 \mathrm{~mm}$

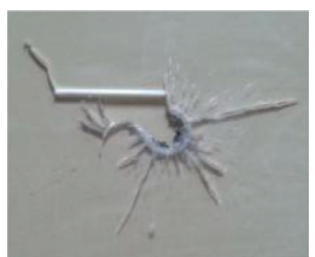

$L=20 \mathrm{~mm}$

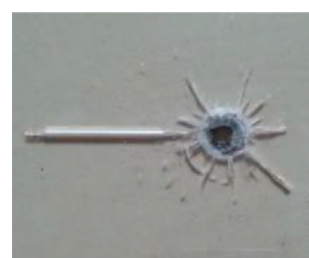

$L=30 \mathrm{~mm}$

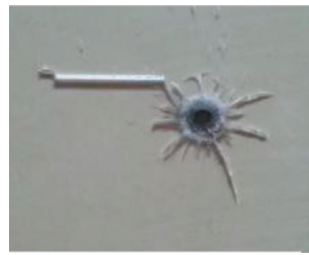

$L=30 \mathrm{~mm}$

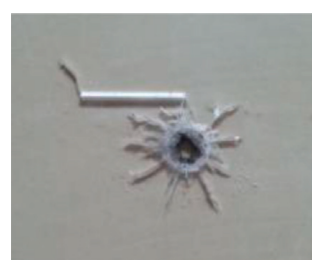

$L=30 \mathrm{~mm}$

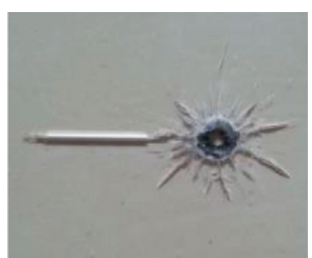

$L=40 \mathrm{~mm}$

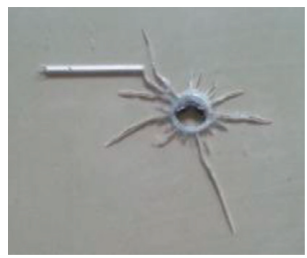

$L=40 \mathrm{~mm}$

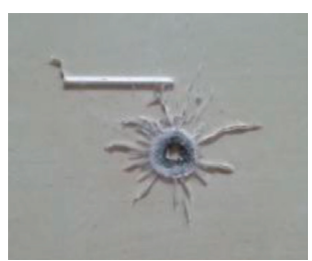

$L=40 \mathrm{~mm}$

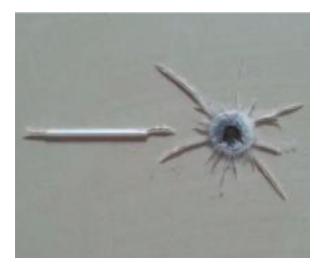

$L=50 \mathrm{~mm}$

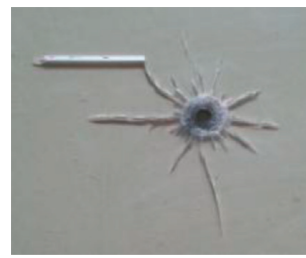

$L=50 \mathrm{~mm}$

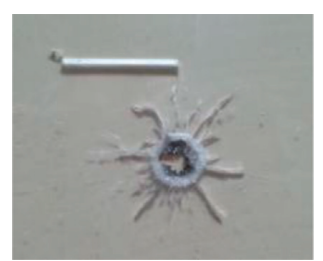

$L=50 \mathrm{~mm}$

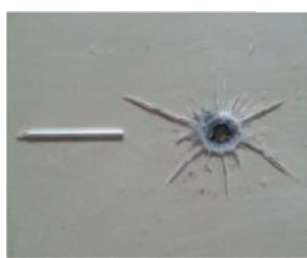

$L=60 \mathrm{~mm}$

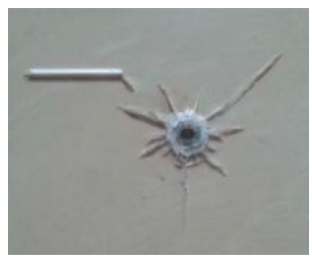

$L=60 \mathrm{~mm}$

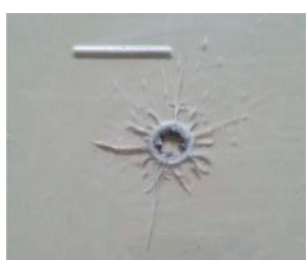

$L=60 \mathrm{~mm}$

Figure 4: Water-filled PMMA specimens after explosion.

TABLE 2: Four kinds of media wave impedance relationship at room temperature.

\begin{tabular}{lcccc}
\hline Medium & $\rho\left(\mathrm{kg} / \mathrm{m}^{3}\right)$ & $c(\mathrm{~m} / \mathrm{s})$ & $\eta\left(\mathrm{kg} /\left(\mathrm{m}^{2} \cdot \mathrm{s}\right)\right)$ & $\Delta \eta\left(\mathrm{kg} /\left(\mathrm{m}^{2} \cdot \mathrm{s}\right)\right)$ \\
\hline PMMA & 1190 & 2320 & $2.7608 \times 10^{6}$ & - \\
Air & 1.25 & 340 & 425 & $2.760375 \times 10^{6}$ \\
Soil & 1800 & 1000 & $1.8 \times 10^{6}$ & $0.9608 \times 10^{6}$ \\
Water & 998 & 1497 & $1.494006 \times 10^{6}$ & $1.266794 \times 10^{6}$ \\
\hline
\end{tabular}

2.3.2. The Influence of Fillings and Angle on the Total Number $N$ of Blast-Induced Cracks. Figure 5 shows the relationship between the total number $N$ of blast-induced cracks exceeded $3 \mathrm{~mm}$ in length and fillings. Due to the minimum discontinuity degree of the air-filled specimen, the preexisting fissure completely blocks the explosive energy, and the reflected stress wave energy is larger, which is favorable for 


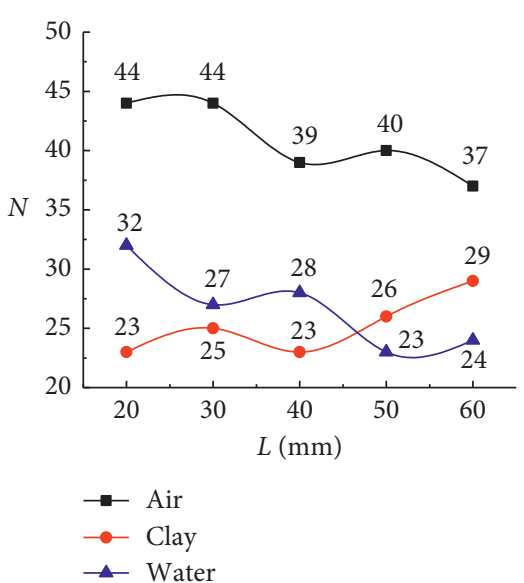

(a)

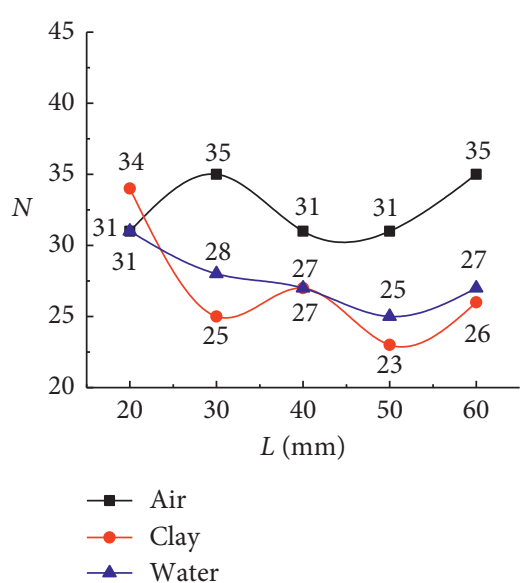

(b)

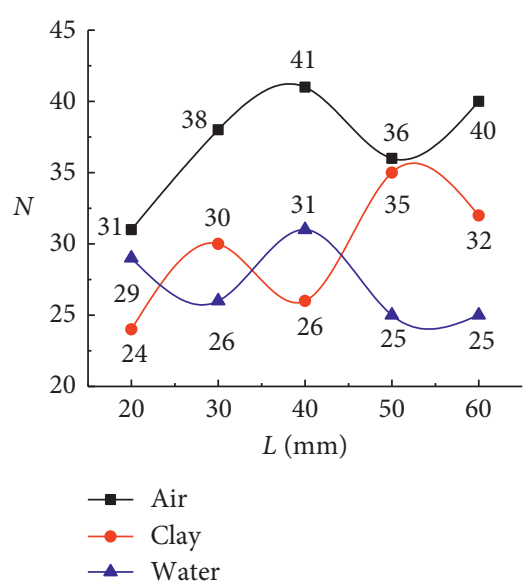

(c)

Figure 5: Relationship between fillings and the total number $N$ of cracks. (a) $\theta=0^{\circ}$; (b) $\theta=45^{\circ}$; (c) $\theta=90^{\circ}$.

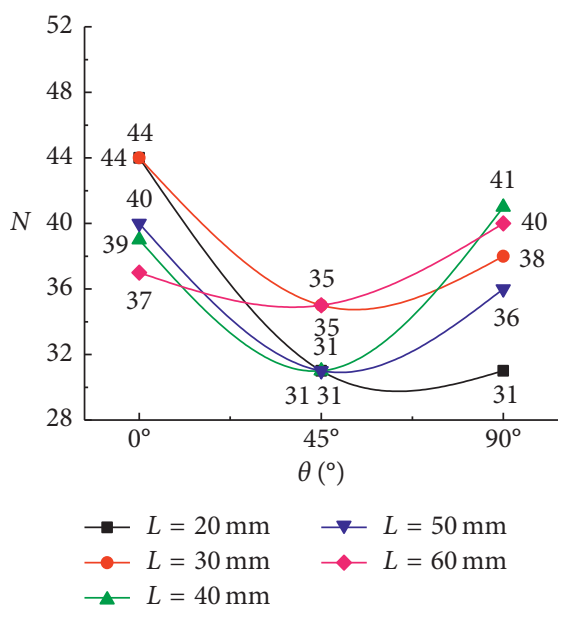

(a)

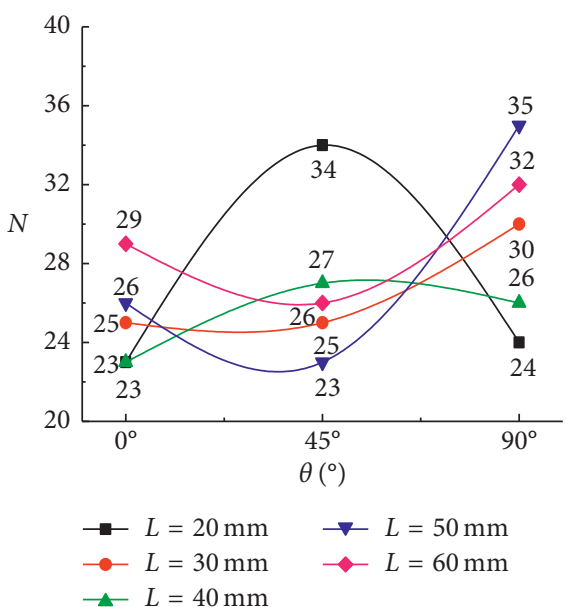

(b)

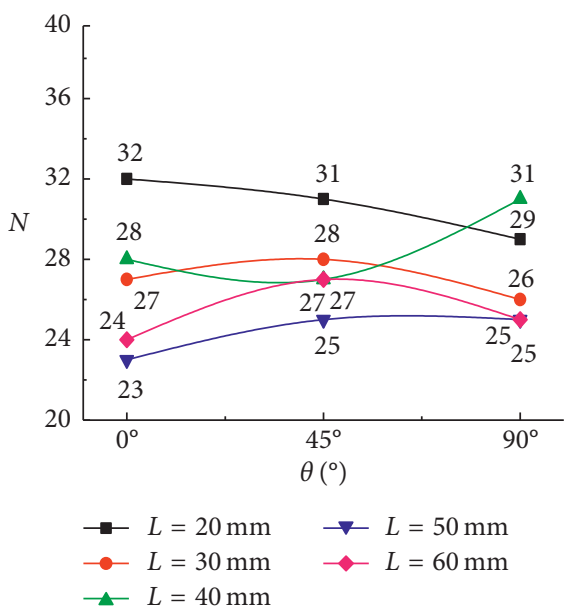

(c)

Figure 6: Relationship between $\theta$ and N. (a) Air; (b) soil; (c) water.

the formation of cracks. The soil-filled and water-filled specimens have the bigger discontinuity degree, and a large amount of compressive stress wave energy is absorbed, so $N$ in the air-filled specimens is substantially larger than that in the other two groups.

As shown in Figure 6, since absorbed stress wave energy at $45^{\circ}$ is larger than that at $0^{\circ}$, and the reflected stress waves mostly travel far away from explosion source. When $\theta$ is $90^{\circ}$, the reflected stress waves mostly travel to explosion source, so $N$ in the air-filled and the other specimens decreases initially and increases afterwards as the angle changes. Compared with the air-filled specimens, due to the bigger discontinuity degree of water-filled specimens, the obtained lower energy of the reflected stress waves restrains the crack propagation, so $N$ in the water-filled specimens first increases and then decreases.

2.3.3. The Wing Crack Analysis. In the actual blasting project, the wing crack propagation in the fissured rock mass seriously affects the rock fragment range and the later engineering support, so it is necessary to analyze the far-end wing crack. In the case of two far-end wing cracks in the $0^{\circ}$ group, for the convenience of studying, the numbers show the average values in Figures 7 and 8.

In Figure 7, the far-end wing crack length in the whole specimens shows a decreasing trend, and the reason is that the tension-shear stress at the crack tip decreases with the increase of $L$, which causes the decrease in length. Because of the minimum discontinuity degree of the air-filled specimen, the far-end wing crack length is larger than that in the soil-filled and water-filled specimens; and the discontinuity degree of the soil-filled and water-filled specimens is relatively bigger and closer, so both the far-end wing cracks are shorter and more similar in length.

In Figure 8, when the angle $\theta$ increases, the loss of energy in the stress wave travel process decreases as the distance from the borehole center to the preexisting fissure far-end decreases, so the far-end wing crack in all the specimens 


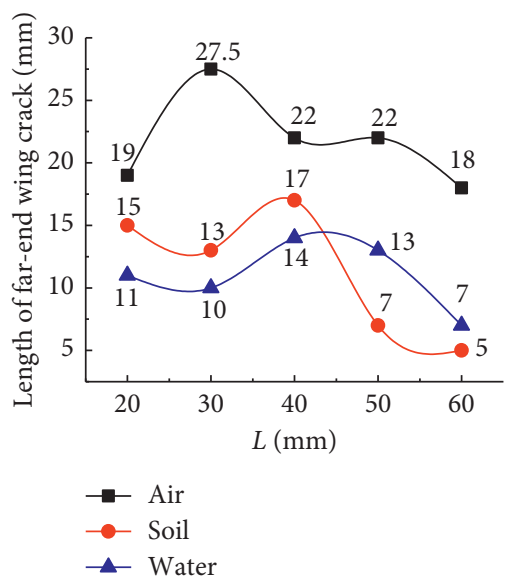

(a)

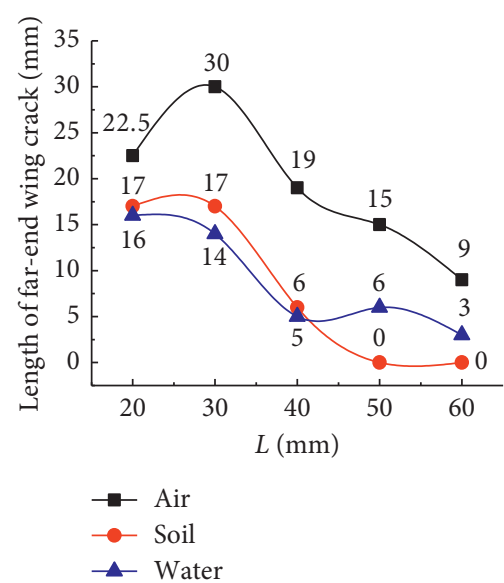

(b)

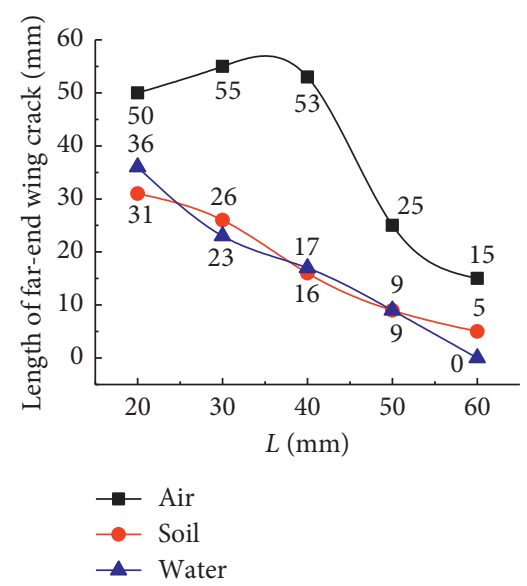

(c)

Figure 7: Relationship between fillings and far-end wing crack. (a) $\theta=0^{\circ}$; (b) $\theta=45^{\circ}$; (c) $\theta=90^{\circ}$.

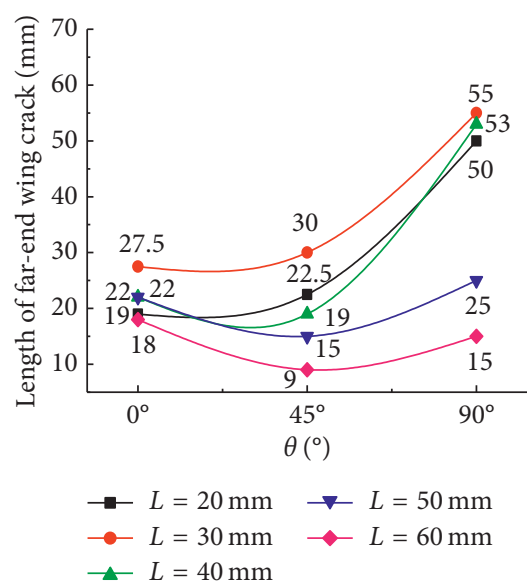

(a)

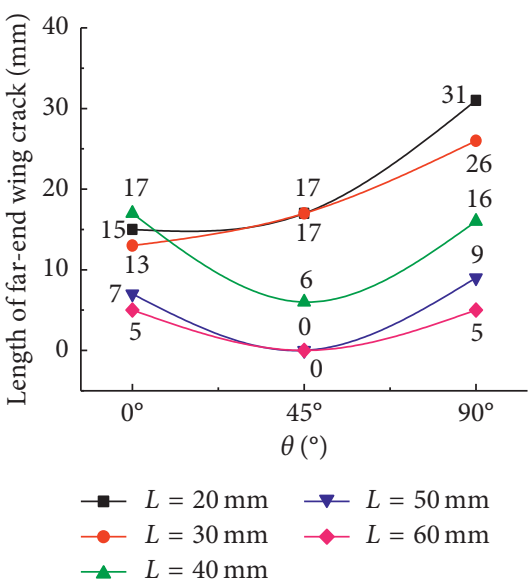

(b)

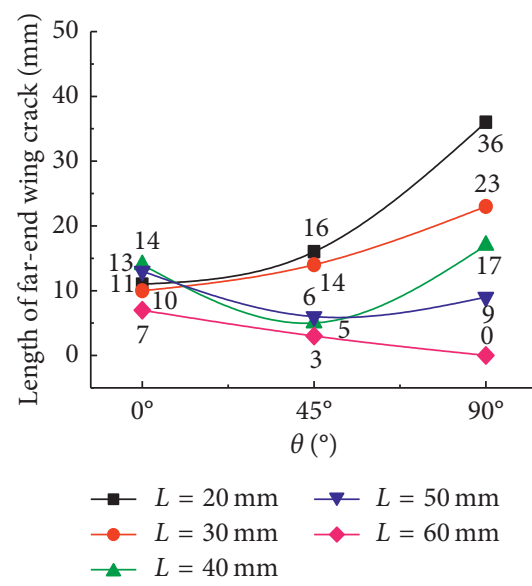

(c)

FIGURE 8: Relationship between $\theta$ and length of the far-end wing crack. (a) Air; (b) soil; (c) water.

increases as the angle increases when $L$ is 20 to $30 \mathrm{~mm}$. When $L$ is 40 to $60 \mathrm{~mm}$, the far-end wing crack first decreases and then increases. The main reasons are as follows: the increase of $L$ leads to the increase of energy loss in the stress wave travel process, compressive stress wave energy is further absorbed by fillings of soil and water, and relatively smaller energy loss in travel is caused because of the closer distance from the borehole center to the preexisting fissure far-end in the $90^{\circ}$ group than that in the $45^{\circ}$ group.

\section{The Numerical Simulation Analysis of Crack Propagation under the Different Fillings}

In order to further reveal the blast-induced crack propagation law in the fissured rock mass under the explosive loads, the nonlinear dynamics software AUTODYN is used for numerical simulation according to the corresponding parameters of the experimental specimen, involving materials including PMMA, fillings (air, soil, and water), and explosive.

\subsection{Material Model}

3.1.1. PMMA. To better cooperate with the tensile crack softening failure model, the linear equation of state (EOS) is applied in PMMA [27]:

$$
P=K\left(\frac{\rho}{\rho_{0}}-1\right)=K \mu,
$$

where $P$ is the explosive pressure, $K$ is the volume modulus of the material, and $\rho / \rho_{0}$ is the ratio of the current density to the initial density during the explosion.

The tensile crack softening model is applied as the PMMA failure model, and the detailed description of this model is in $[16,27,28]$. Generally, the relevant physical and mechanical parameters of PMMA under the dynamic loads are difficult to measure, which is related to the material properties, experimental conditions, temperature, and so on. So the author revised some parameters according to the parameters listed in [13], as shown in Tables 3 and 4 [29, 30]. 
Table 3: Dynamic parameters of PMMA.

\begin{tabular}{lcccccc}
\hline $\begin{array}{l}\text { Density, } \\
\rho\left(\mathrm{kg} / \mathrm{m}^{3}\right)\end{array}$ & $\begin{array}{c}\text { Poisson's } \\
\text { ratio, } v\end{array}$ & $\begin{array}{c}\text { Dynamic elastic } \\
\text { modulus, } E_{\mathrm{d}}(\mathrm{Pa})\end{array}$ & $\begin{array}{c}\text { Dynamic shear } \\
\text { modulus, } G_{\mathrm{d}}(\mathrm{Pa})\end{array}$ & $\begin{array}{c}\text { Dynamic bulk } \\
\text { modulus, } K_{\mathrm{d}}(\mathrm{Pa})\end{array}$ & $\begin{array}{c}\mathrm{P} \text { wave } \\
\text { velocity, } C_{\mathrm{p}}(\mathrm{m} / \mathrm{s})\end{array}$ & $\begin{array}{c}\mathrm{S} \text { wave } \\
\text { velocity, } C_{\mathrm{s}}(\mathrm{m} / \mathrm{s})\end{array}$ \\
\hline 1190 & 0.31 & $6.1 e 9$ & $2.328 e 9$ & $5.35 e 9$ & 2320 & 1260 \\
\hline
\end{tabular}

TABLE 4: Strength parameters of PMMA.

\begin{tabular}{lcc}
\hline $\begin{array}{l}\text { Dynamic tensile } \\
\text { strength, } \sigma_{\mathrm{T}}(\mathrm{Pa})\end{array}$ & $\begin{array}{c}\text { Dynamic shear } \\
\text { strength, } \tau_{\mathrm{c}}(\mathrm{Pa})\end{array}$ & $\begin{array}{c}\text { Fracture energy, } \\
G_{\mathrm{c}}\left(\mathrm{J} / \mathrm{m}^{2}\right)\end{array}$ \\
\hline $45 e 6$ & $80 e 6$ & 133 \\
\hline
\end{tabular}

\subsubsection{Fillings}

(a) Air

For air, the EOS is described by the ideal gas:

$$
P=(\gamma-1) \rho e,
$$

where $P$ is the pressure; $\gamma$ is the adiabatic exponent, $1.4 ; \rho$ is the density, $1.25 \mathrm{~kg} / \mathrm{m}^{3}$; and $e$ is the internal energy.

(b) Soil

The soil is described by the shock EOS and the Drucker-Prager strength model. The concrete parameters are shown in Table 5 [31].

(c) Water

A polynomial EOS is applied to water:

For $\mu>0$ (compression),

$$
P=A_{1} \mu+A_{2} \mu^{2}+A_{3} \mu^{3}+\left(B_{0}+B_{1} \mu\right) \rho_{0} e .
$$

For $\mu<0$ (tension),

$$
P=T_{1} \mu+T_{2} \mu^{2}+B_{0} \rho_{0} e
$$

where in the above two formulas $P$ is the pressure, $\rho_{0}$ is the density, $e$ is the internal energy, and $A_{1}, A_{2}, A_{3}, B_{0}, B_{1}, T_{1}$, and $T_{2}$ are the constants, and the specific parameters are shown in Table 6.

3.1.3. Explosive. The explosive is ammonium nitrate-fuel oil (ANFO) explosive, and the EOS is described by JWL:

$$
P=A\left(1-\frac{\omega}{R_{1} V}\right) e^{-R_{1} V}+B\left(1-\frac{\omega}{R_{2} V}\right) e^{-R_{2} V}+\frac{\omega e}{V},
$$

where $P$ is the pressure, $e$ is the initial internal energy of the explosive product, $V$ is the relative volume, and $A$, $B, R_{1}$, and $R_{2}$ are the constants. The material parameters of ANFO are listed in Table 7.

3.2. Material Location and Grid Mesh. According to the experimental specimen, the 2D model and noncoupling charge structure are applied. The diameters of the borehole and explosive are $7 \mathrm{~mm}$ and $6 \mathrm{~mm}$, respectively. A variety of grid sizes were applied to simulate the crack propagation, and we found that too big or too small grid sizes would lead to unsatisfactory or nonideal crack results compared with the experimental crack results. Meanwhile, we also did the convergence computation through all kinds of grid sizes. Based on the above previous works before simulation, we chose $1.5 \mathrm{~mm}$ as the grid size at last and the total number elements were 78655 . The mesh method is sweep, the boundary condition is the free boundary, and the calculation time is $100 \mu \mathrm{s}$. The location of the materials and the mesh are shown in Figure 9.

3.3. Simulation Results. The numerical simulation results are shown in Figures 10-12. Due to the high explosive pressure on the borehole wall, a crushed zone develops near the borehole and a fractured zone also develops because of the radial cracks generation after the formation of the crushed zone. Blast-induced cracks almost cannot get over the preexisting fissure to continue to propagate, and the wing cracks appear at both ends of the preexisting fissure. It should be noted that the far-end wing cracks propagate horizontally at $\theta=0^{\circ}$, while the far-end wing cracks propagate above obliquely at $\theta=45^{\circ}$ and $\theta=90^{\circ}$. Additionally, the crack is produced on the other side of the preexisting fissure in the air-filled specimen of $L=30 \mathrm{~mm}$ at $\theta=45^{\circ}$. All these phenomena appearing in numerical simulation agree basically with the experimental phenomena.

\subsection{The Blasting-Induced Crack Propagation Mechanism.} Because the explosion of the detonator in experiment has less gas and the calculation time is relatively shorter in numerical simulation, it is considered that the stress wave is the most important factor in blast-induced crack initiation and propagation. From the experimental and simulative results, it can be concluded that the crack propagation process can be divided into two stages through the time points that whether the reflected stress wave formed in the preexisting fissure has common interaction with the compressive stress wave or not. The first is the phase of the compressive stress wave, and the second is the phase of the common interaction between compressive stress wave and reflected stress wave.

\subsubsection{The Radial Crack Propagation Mechanism around the} Borehole. After detonator or explosive detonation, the shock wave compresses on the borehole wall intensely to develop the crushed zone around the borehole because of the shear stress. The shock wave attenuates the stress wave during the process of the crushed zone formation. The stress wave compresses radially the media outside the crushed zone to cause the tangential stress, and once the tangential stress reaches the dynamic tensile strength of the medium, it will lead to radial crack initiation and propagation. Then, the reflected stress wave and the compressive stress wave act together to promote the crack propagation again. 
TABLE 5: Parameters of the soil model.

\begin{tabular}{|c|c|c|c|c|c|c|c|c|c|c|c|}
\hline $\begin{array}{l}\text { Density, } \\
\rho\left(\mathrm{kg} / \mathrm{m}^{3}\right)\end{array}$ & $\begin{array}{l}\text { Grüneisen } \\
\text { gamma, } \Gamma\end{array}$ & $\begin{array}{c}C 1 \\
(\mathrm{~m} / \mathrm{s})\end{array}$ & $S$ & $\begin{array}{c}\text { Shear } \\
\text { modulus, } \\
G(\mathrm{~Pa})\end{array}$ & $\begin{array}{c}\text { Pressure } \\
1(\mathrm{~Pa})\end{array}$ & $\begin{array}{c}\text { Pressure } \\
2(\mathrm{~Pa})\end{array}$ & $\begin{array}{c}\text { Pressure } \\
3(\mathrm{~Pa})\end{array}$ & $\begin{array}{l}\text { Yield } \\
\text { stress } \\
1(\mathrm{~Pa}) \\
\end{array}$ & $\begin{array}{l}\text { Yield } \\
\text { stress } \\
2(\mathrm{~Pa}) \\
\end{array}$ & $\begin{array}{l}\text { Yield } \\
\text { stress } \\
3(\mathrm{~Pa}) \\
\end{array}$ & $\begin{array}{l}\text { Hydrotensile } \\
\text { limit }(\mathrm{Pa})\end{array}$ \\
\hline 1800 & 0.11 & 1614 & 1.5 & $0.24 e 9$ & $-1.149 e 6$ & $6.88 e 6$ & $1 e 13$ & 0 & $6.88 e 6$ & $6.2 e 6$ & $-100 e 3$ \\
\hline
\end{tabular}

TABle 6: Parameters of the water model.

\begin{tabular}{lccccccc}
\hline Density, $\rho_{0}\left(\mathrm{~kg} / \mathrm{m}^{3}\right)$ & $A_{1}(\mathrm{~Pa})$ & $A_{2}(\mathrm{~Pa})$ & $A_{3}(\mathrm{~Pa})$ & $B_{0}$ & $B_{1}$ & $T_{1}(\mathrm{~Pa})$ & $T_{2}(\mathrm{~Pa})$ \\
\hline 998 & $2.2 e 9$ & $9.54 e 9$ & $14.57 e 9$ & 0.28 & 0.28 & $2.2 e 9$ & 0 \\
\hline
\end{tabular}

TABle 7: Parameters of ANFO.

\begin{tabular}{|c|c|c|c|c|c|c|c|}
\hline Density, $\rho\left(\mathrm{kg} / \mathrm{m}^{3}\right)$ & Detonation velocity $(\mathrm{m} / \mathrm{s})$ & $C-J$ pressure $(\mathrm{Pa})$ & $A(\mathrm{~Pa})$ & $B(\mathrm{~Pa})$ & $R_{1}$ & $R_{2}$ & $\omega$ \\
\hline 931 & 4160 & $5.15 \mathrm{e} 9$ & $5.15 \mathrm{e} 9$ & $1.891 \mathrm{e} 9$ & 3.907 & 1.18 & 0.333 \\
\hline
\end{tabular}

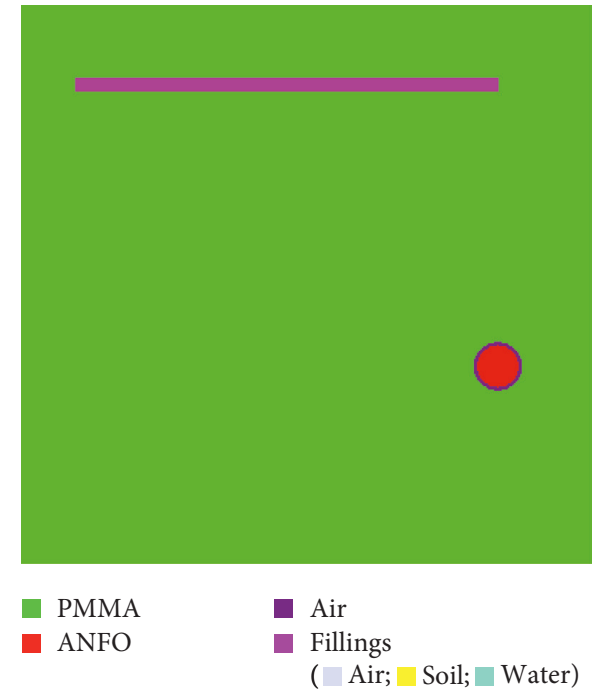

(a)

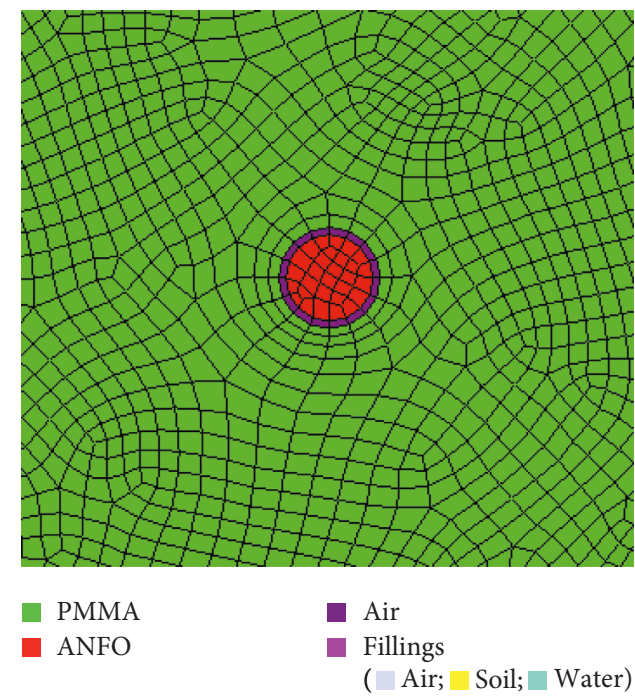

(b)

FIgURE 9: (a) Material location; (b) gird mesh.

Considering the different positions between preexisting fissure and borehole, the reflected stress wave that travels back to the borehole is different, and radial crack propagation mechanism is also different, so it is necessary to discuss the influence of the distance, angle, and fillings on crack propagation.

\section{(1) Distance $L$}

In numerical simulation, take the air-filled specimens at $\theta=90^{\circ}$ as an example and choose the element as the gauss point at $10 \mathrm{~mm}$ below the preexisting fissure center from $L=20$ to $60 \mathrm{~mm}$; the relationship between the peak pressure and $L$ is shown in Figure 13. It shows the law that the peak pressure decreases when $L$ increases.

\section{(2) Angle $\theta$}

When $\theta=0^{\circ}$, the compressive stress wave travels parallely to the preexisting fissure, and the reflected stress wave at the proximal end almost does not act on crack propagation, so the crack is mostly caused by the compressive stress wave; when $\theta=45^{\circ}$, the compressive stress wave travels obliquely to the preexisting fissure, and the reflected stress wave travels far from the media around the borehole, in which another small part of the reflected stress wave has limited effect on the propagation and initiation of crack; when $\theta=90^{\circ}$, the compressive stress wave travels vertically to the preexisting fissure, and the more reflected stress wave can help to crack propagation. Therefore, the increase of the angle $\theta$ is beneficial to the crack propagation.

\section{(3) Fillings}

When $\theta=90^{\circ}$ and $L=50 \mathrm{~mm}$, the element is also selected as the gauss point at $10 \mathrm{~mm}$ below the preexisting fissure center of the three fillings specimens. As $L$ is the same, theoretically compressive stress wave peak pressure should also be basically the same. To reflect the influence of fillings on the reflected stress wave, take the peak pressure of stress wave pressure as a reference, as shown in Figure 14. The peak 


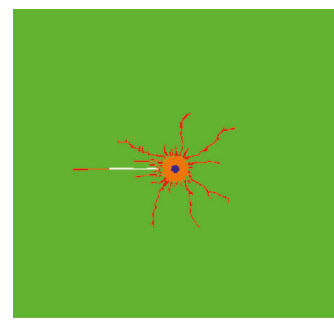

$L=20 \mathrm{~mm}$

Air

- PMMA

- ANFO and air products

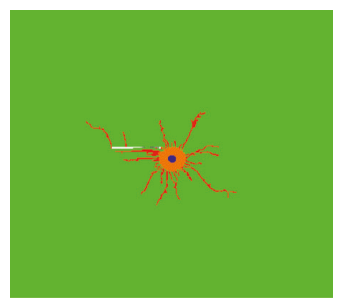

$L=20 \mathrm{~mm}$

Air

- PMMA

- ANFO and air products

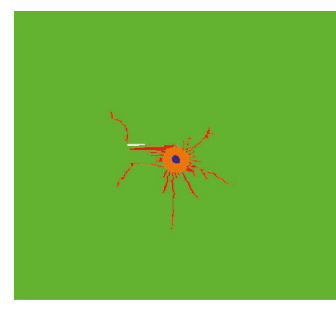

$L=20 \mathrm{~mm}$

air

PMMA

ANFO and air products

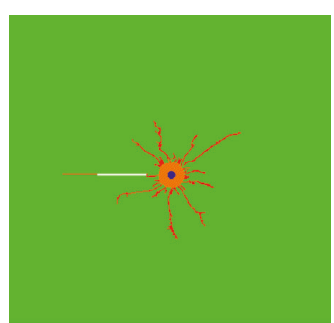

$L=30 \mathrm{~mm}$

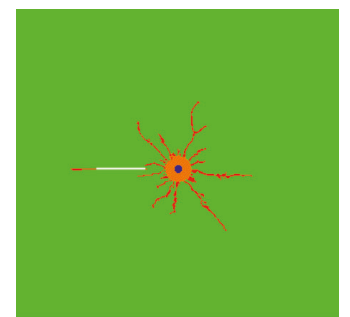

$L=40 \mathrm{~mm}$

Blast-induced crack (tensile failure)

- Crushed zone (shear failure)

(a)

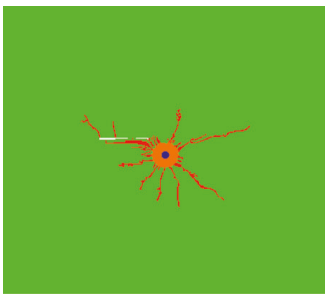

$L=30 \mathrm{~mm}$

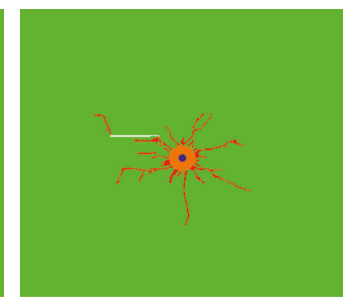

$L=40 \mathrm{~mm}$

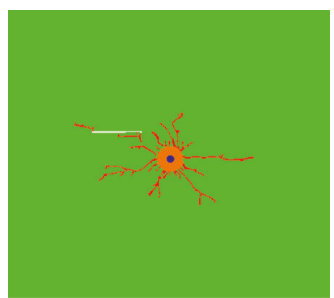

$L=50 \mathrm{~mm}$

Blast-induced crack (tensile failure)

- Crushed zone (shear failure)

(b)

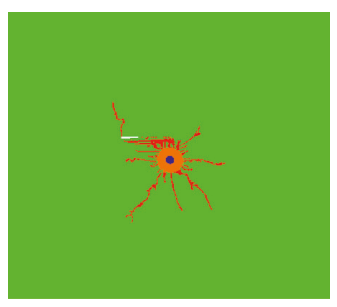

$L=30 \mathrm{~mm}$

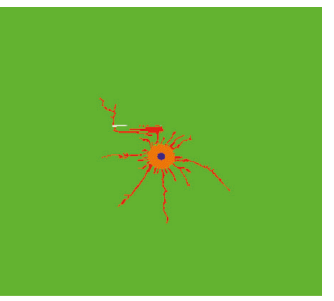

$L=40 \mathrm{~mm}$

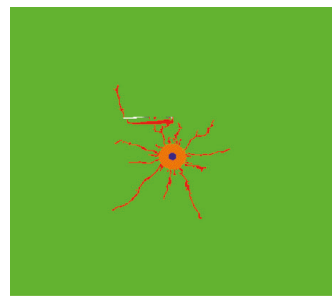

$L=50 \mathrm{~mm}$

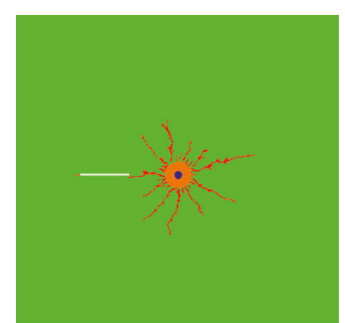

$L=60 \mathrm{~mm}$

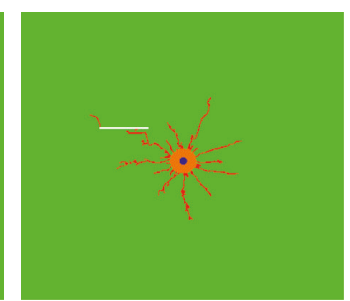

$L=60 \mathrm{~mm}$

- Blast-induced crack (tensile failure)

- Crushed zone (shear failure)

(c)

Figure 10: Material status of air-filled PMMA after explosion. (a) $\theta=0^{\circ}$; (b) $\theta=45^{\circ}$; (c) $\theta=90^{\circ}$.

value of the reflected stress wave in the air-filled specimen is maximum, which shows that the air-filled specimens are more conducive to the crack propagation than the soil-filled and water-filled specimens; comparing the peak value of the reflected stress wave with $\Delta \eta$ (the difference value of wave impedance between the three kinds of fillings and PMMA), it can be seen that the peak pressure value increases with the increase of $\Delta \eta$, which further indicates that it is valid to use the difference value of wave impedance to measure the discontinuity degree of the specimen and adopt the discontinuity degree to explain the phenomena of crack propagation.

3.4.2. The Wing Crack Propagation Mechanism. In numerical simulation, the damage-time curve is obtained by setting the initiation point of the far-end wing crack as the gauss point. Taking the air-filled specimen at $\theta=45^{\circ}$ and $L=20 \mathrm{~mm}$ as the example, the damage value of this specimen is fitted by S-logistic function, as shown in Figure 15, and the fitting function is

$$
D=\frac{1}{\left[1+\left(4.21 \times 10^{-5} / t\right)^{11065.77665}\right]^{0.09123}}
$$

where $t$ is the time (s) and $D$ is the damage. By fitting the curve, it can be seen that the damage value is the "S" curve changing with time. According to the characteristics of change in the fitting curve, damage evolution is divided into three stages: OA stage is the early stage of damage, and the damage relatively increases more slowly with time; $A B$ stage is the middle stage of damage, and the damage value increases rapidly in the short time; $\mathrm{BC}$ stage is the late stage of damage because the damage value of $B$ point is close to 1 , so 


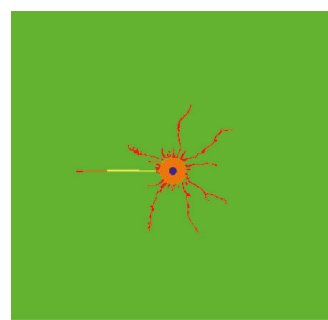

$L=20 \mathrm{~mm}$

Soil

- PMMA

- ANFO and air products

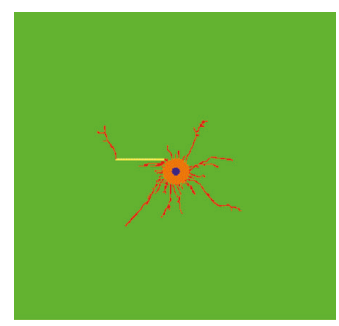

$L=20 \mathrm{~mm}$

- Soil

PMMA

- $\mathrm{ANFO}$ and air products

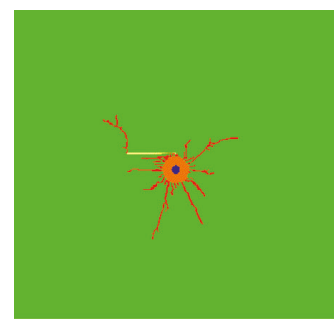

$L=20 \mathrm{~mm}$

- Soil

PMMA

- ANFO and air products

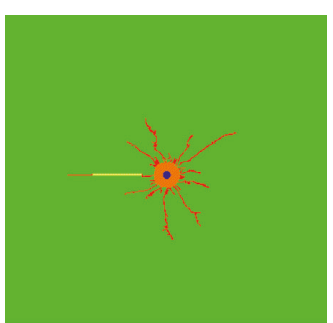

$L=30 \mathrm{~mm}$

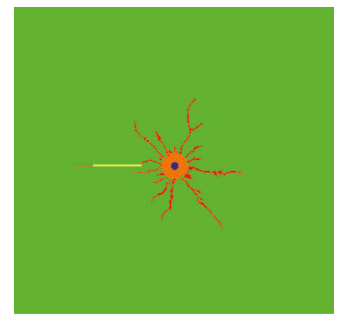

$L=40 \mathrm{~mm}$

- Blast-induced crack (tensile failure)

- Crushed zone (shear failure)

(a)

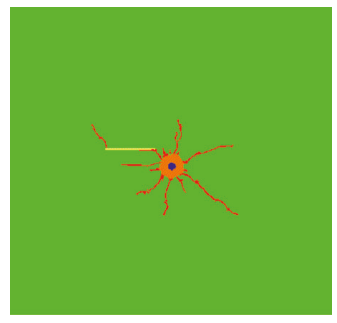

$L=30 \mathrm{~mm}$

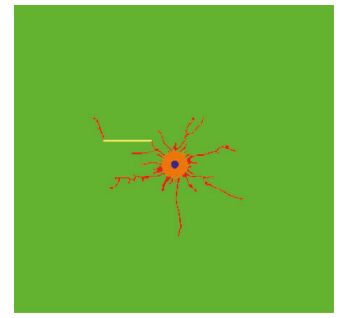

$L=40 \mathrm{~mm}$

Blast-induced crack (tensile failure)

- Crushed zone (shear failure)

(b)

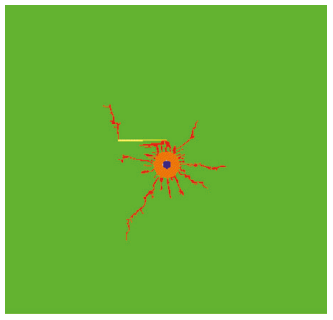

$L=30 \mathrm{~mm}$

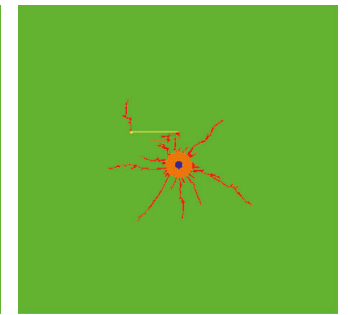

$L=40 \mathrm{~mm}$

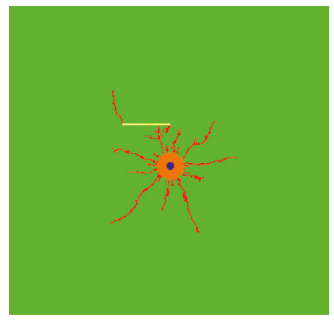

$L=50 \mathrm{~mm}$

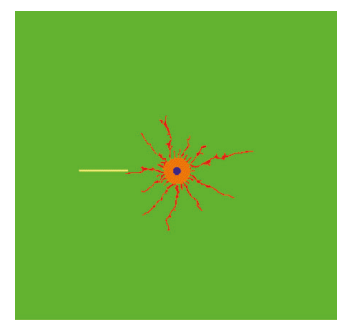

$L=60 \mathrm{~mm}$

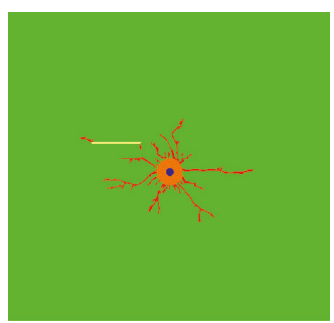

$L=50 \mathrm{~mm}$

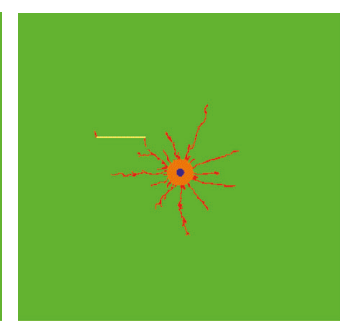

$L=60 \mathrm{~mm}$

- Blast-induced crack (tensile failure)

- Crushed zone (shear failure)

(c)

Figure 11: Material status of soil-filled PMMA after explosion. (a) $\theta=0^{\circ}$; (b) $\theta=45^{\circ}$; (c) $\theta=90^{\circ}$.

in a very short time the damage value achieves 1 , but this stage curve changes slowly, and it can be speculated that the damage growth rate decreases. Overall, the damage-time experiences the evolution process that OA stage keeps an upward trend but in a less significant way, AB stage shows an obvious soar trend, and then BC stage rises moderately.

The dynamic tensile damage evolution process is reflected fully in Figure 16; namely, there are two growth stages of significant difference in the tensile damage evolution: one is the $\mathrm{AB}$ phase of nonlinear fast growth, the other is the $\mathrm{BC}$ phase of linear growth, and the transition of the two stages has an obvious critical characteristic. When the initiation point of the far-end wing crack is subjected to tensile force, damage occurs, so initial damage point A occurs at the tension stage, but the tensile force at point $A$ is not the peak value. Once the damage occurs, the damage will experience a rapid nonlinear growth to the turning point $\mathrm{B}$, whose corresponding tensile force is the peak value; the damage increases linearly when the tensile force decreases, and finally, the damage value reaches 1 when the medium becomes totally fractured.

Figure 17 shows the typical pressure-time history curves at different angles of the initiation point of the far-end wing crack in the air-filled specimen at $L=20 \mathrm{~mm}$. The compressive stress wave acts on the initiation point before the reflected stress wave and the diffracted stress wave in the preexisting fissure, so firstly the initiation point is subjected to the pressure and then the tensile force. With the increase of the angle, the distance from the borehole to the crack initiation point decreases and the compressive stress wave peak value increases, but the tensile force peak value 


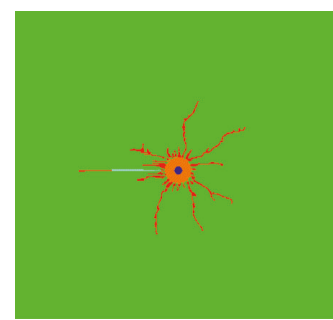

$L=20 \mathrm{~mm}$

Water

- PMMA

- ANFO and air products

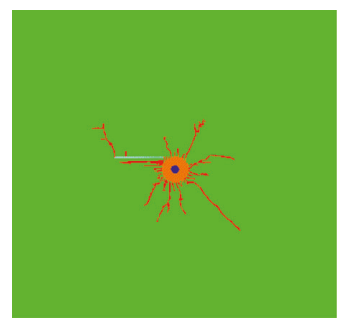

$L=20 \mathrm{~mm}$

Water

- PMMA

ANFO and air products

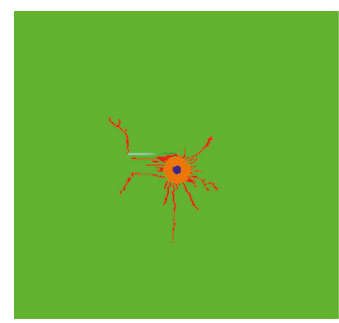

$L=20 \mathrm{~mm}$

Water

- PMMA

- ANFO and air products

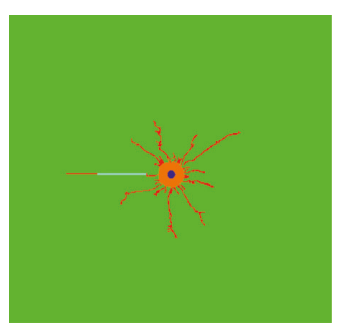

$L=30 \mathrm{~mm}$

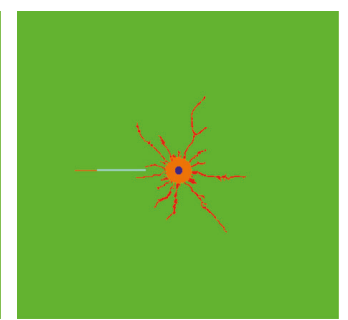

$L=40 \mathrm{~mm}$

- Blast-induced crack (tensile failure)

- Crushed zone (shear failure)

(a)

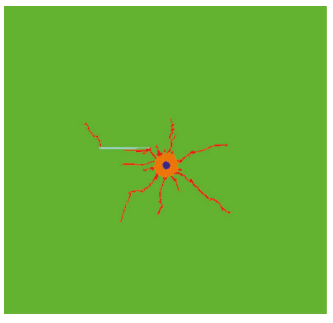

$L=30 \mathrm{~mm}$

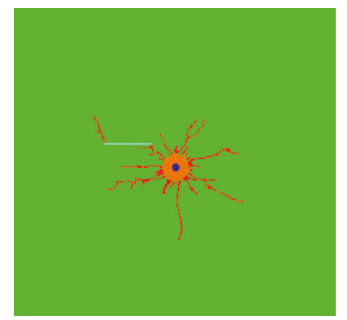

$L=40 \mathrm{~mm}$

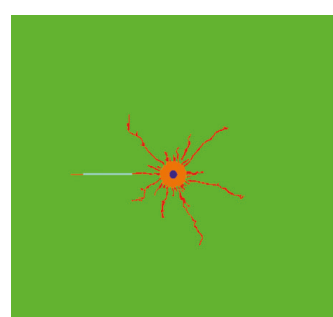

$L=50 \mathrm{~mm}$

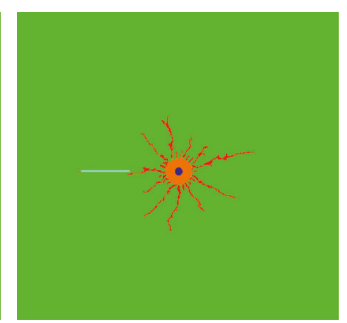

$L=60 \mathrm{~mm}$

- Blast-induced crack (tensile failure)

- Crushed zone (shear failure)

(b)

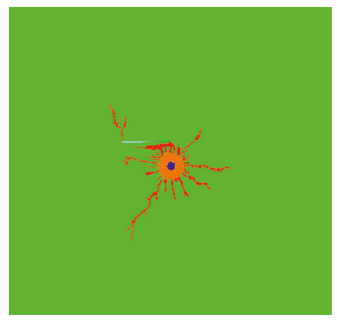

$L=30 \mathrm{~mm}$

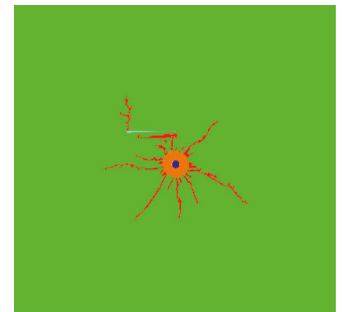

$L=40 \mathrm{~mm}$

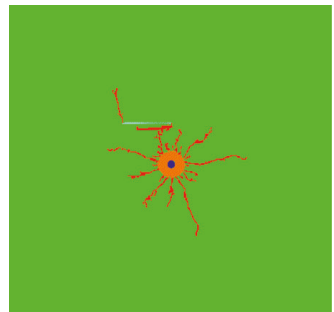

$L=50 \mathrm{~mm}$

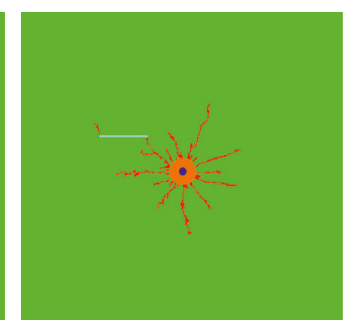

$L=60 \mathrm{~mm}$

- Blast-induced crack (tensile failure)

- Crushed zone (shear failure)

(c)

Figure 12: Material status of water-filled PMMA after explosion. (a) $\theta=0^{\circ}$; (b) $\theta=45^{\circ}$; (c) $\theta=90^{\circ}$.

decreases. The reason is that the reflected stress wave has a serious impact on the subsequent compressive stress wave, which results in reduction of the tensile force peak when the phenomenon of two kinds of stress wave superimposition appears. Additionally, it is also found that peak pressure decreases faster than the tensile force peak at the far-end initiation point, and the whole pressure-time decreases when the angle increases.

The effects of distance, angle, and fillings on the initial damage and fracture time of the initiation point of the farend wing crack are discussed below. Generally, the distance that the stress wave travels to the far end of the preexisting fissure also increases as the distance $L$ increases, which causes the delay of initial damage and fracture time of the far-end wing crack initiation point. If the angle $\theta$ increases, the initial damage and fracture time of the initiation point is earlier, and the distance that the stress wave travels to the far end of the preexisting fissure decreases as the angle $\theta$ increases. When the fillings change, it can be seen that the initial damage and fracture time of the far-end wing crack initiation point in the air-filled specimen is the earliest and the soil-filled specimen is the latest, and the reason is that the smaller the $\Delta \eta$ value is, the larger the discontinuity degree is and the more the energy absorption of the compressive stress wave is, so the initial damage and fracture time is different.

The compressive stress wave travels to the preexisting fissure, and the pressures are firstly generated at the initiation points of the both ends. The pressure is gradually converted to the tensile force as the reflected stress wave generated in the prefabricated crack continues to pressure 


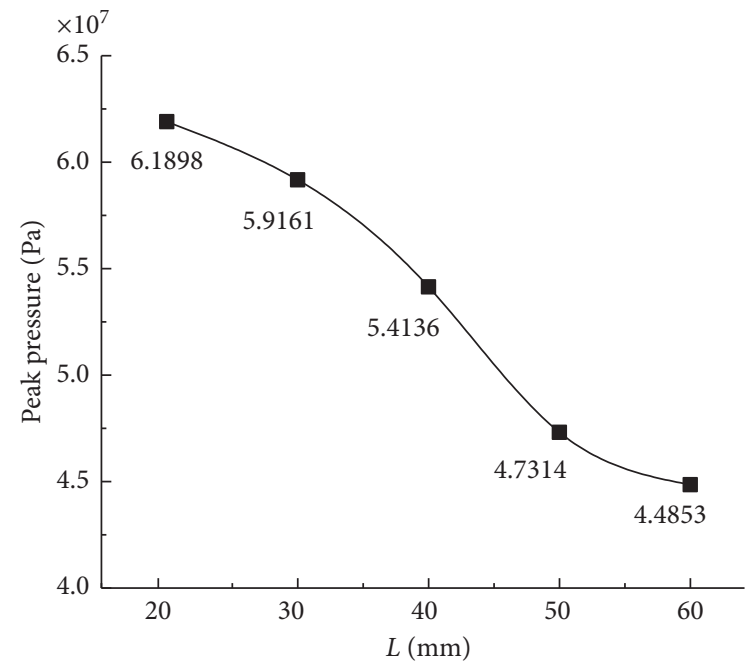

FIgURE 13: Relationship between peak pressure and $L$.

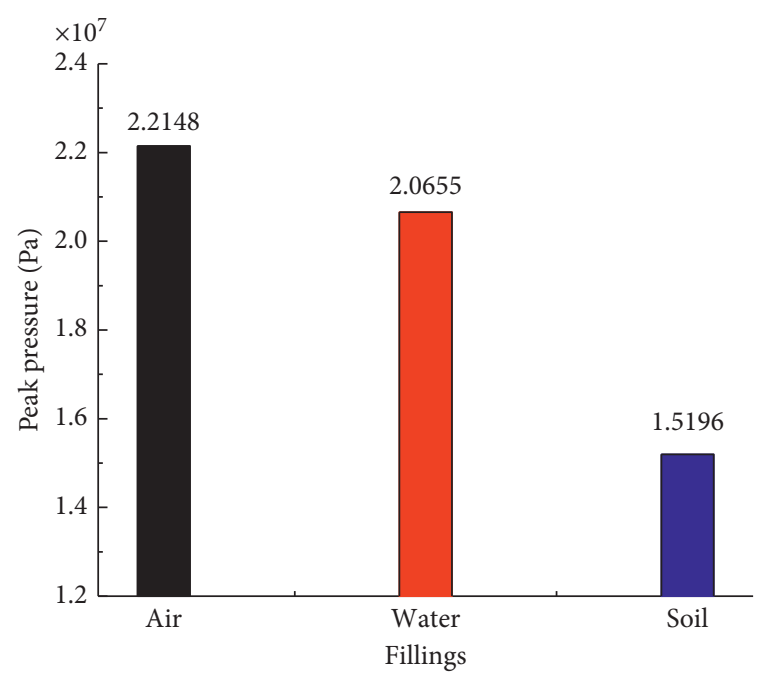

FIGURE 14: Relationship between peak pressure and fillings.

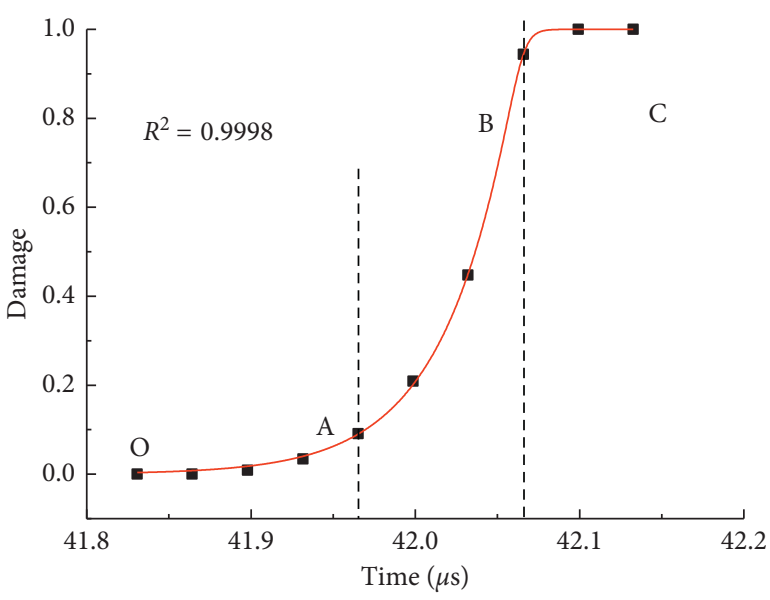

- Calculated value

- Fitting curve

FIgURE 15: The fitting curve of damage-time in the air-filled specimen at $45^{\circ}$ and $L=20 \mathrm{~mm}$.

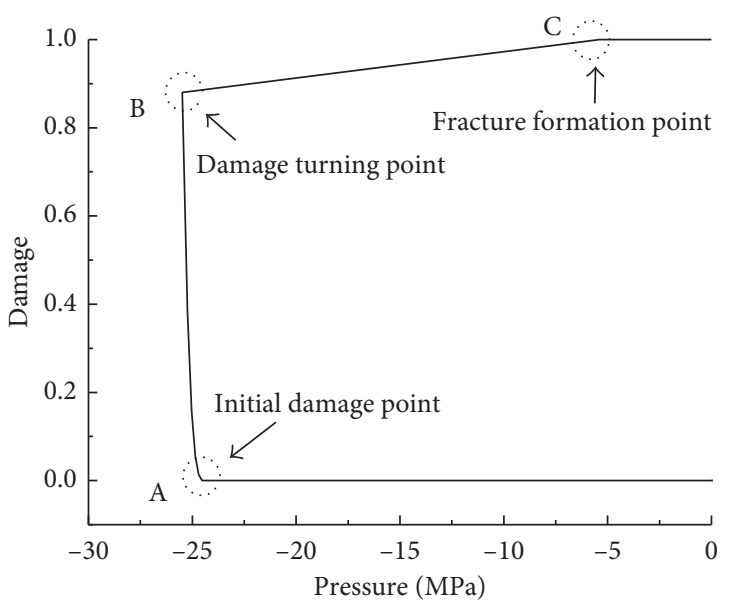

FIGURE 16: The curve of damage-pressure in the air-filled specimen at $0^{\circ}$ and $L=20 \mathrm{~mm}$.

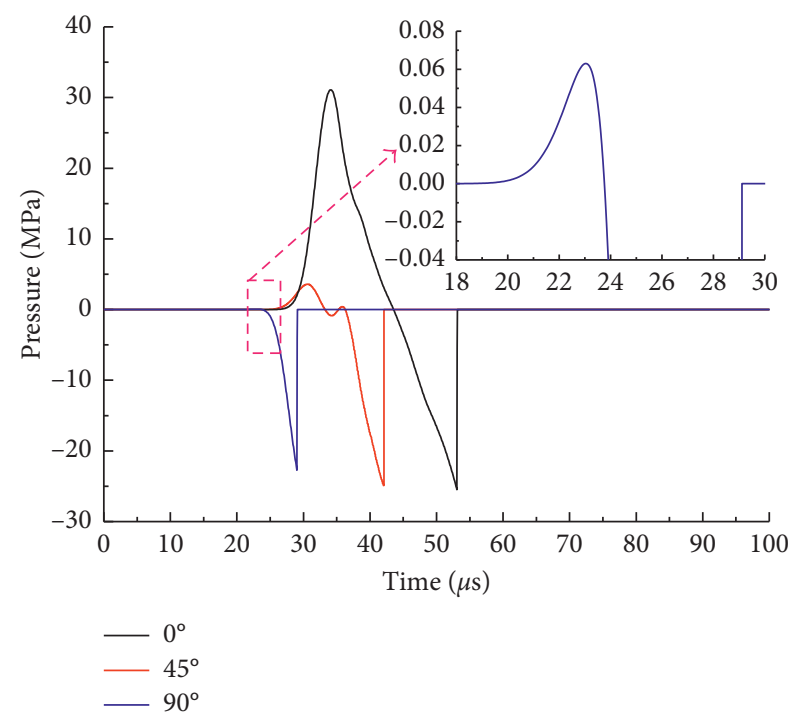

FIgURE 17: Typical curves of pressure-time at different angles (airfilled specimens at $L=20 \mathrm{~mm}$ ).

on initiation points. As time goes on, the initiation point begins to damage, and the damage value increases rapidly, and finally the damage value reaches 1 . During the whole process, the stress concentration occurs at the crack initiation point. When the stress strength exceeds the dynamic tensile strength of PMMA, the wing cracks begin to initiate and propagate. In the crack propagation process, the shear stress is produced by the shear-slip caused by the uneven stress at the crack tip, which indicates that the wing crack propagates in a tensile-shear mode. When the stress strength is lower than the dynamic initiation strength, the wing crack arrests.

Through the analysis of the physical experiment and numerical simulation, for most of the specimens, the wing crack propagation direction exists in two situations: when the distance $L$ is relatively smaller $(L=20-30 \mathrm{~mm})$, the blastinduced crack outside the crushed zone directly propagates through the proximal end of preexisting fissure; when the 


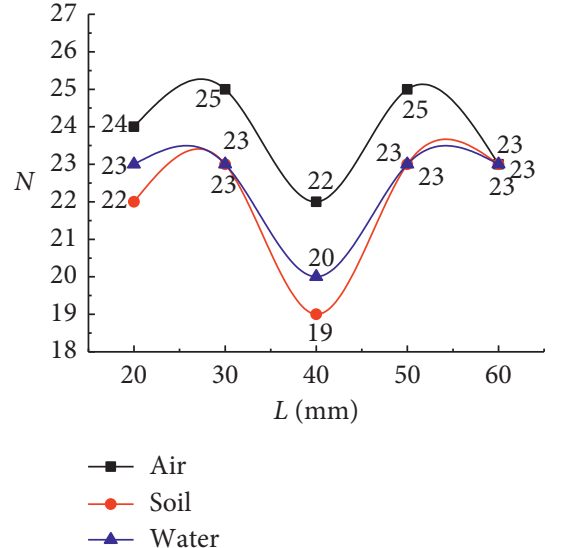

(a)

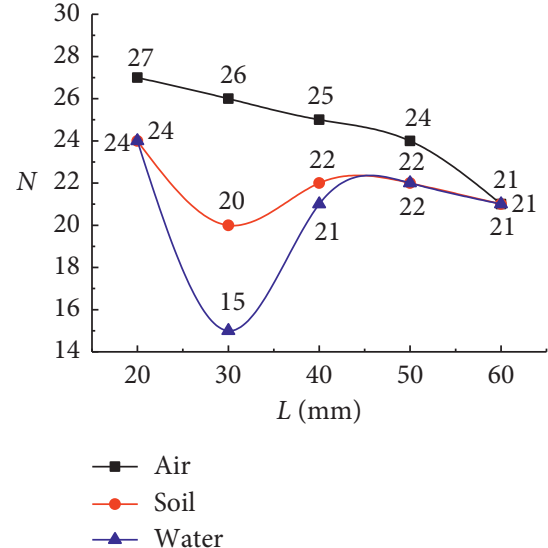

(b)

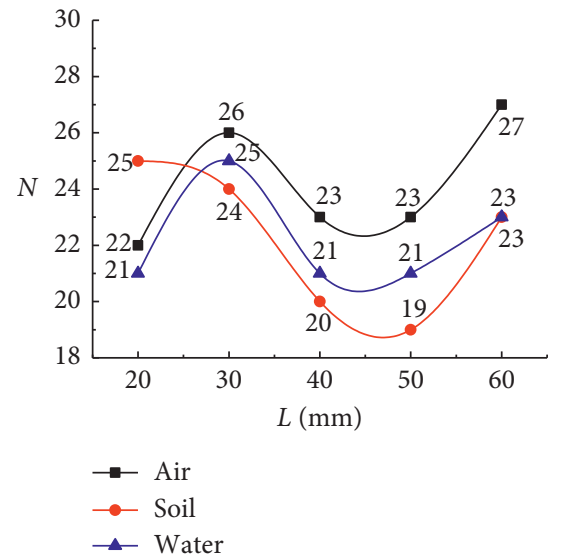

(c)

Figure 18: Relationship between fillings and the total number $N$ of cracks in numerical simulation. (a) $\theta=0^{\circ}$; (b) $\theta=45^{\circ}$; (c) $\theta=90^{\circ}$.

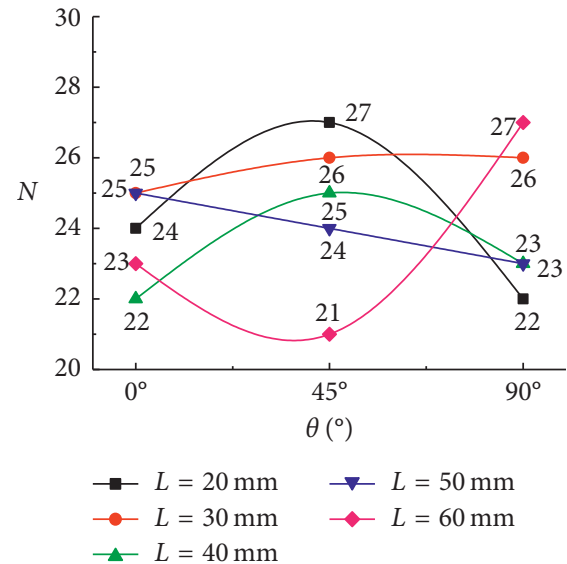

(a)

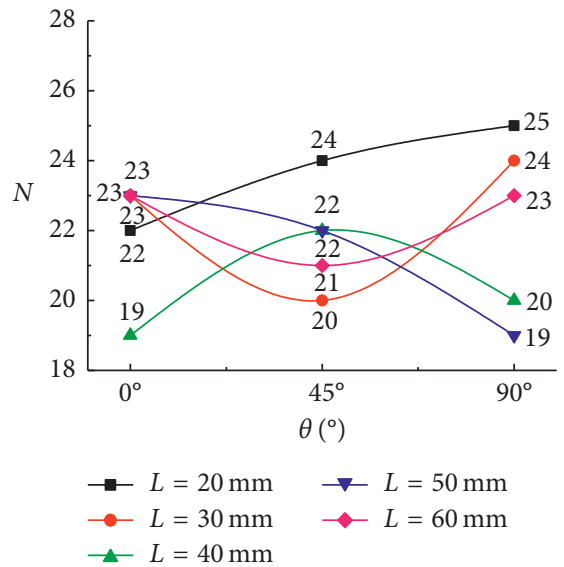

(b)

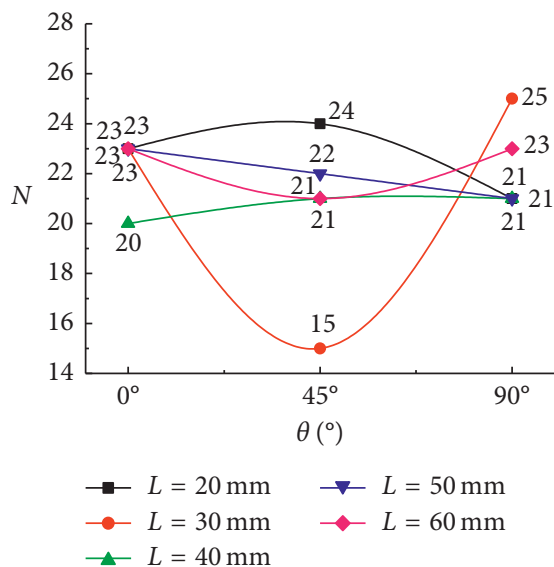

(c)

Figure 19: Relationship between $\theta$ and the total number $N$ of cracks in numerical simulation. (a) Air; (b) soil; (c) water.

distance $L$ is relatively larger $(L=40-60 \mathrm{~mm})$, the proximalend wing crack propagates toward the borehole. However, far-end wing cracks propagate away from the borehole in all the specimens. Meanwhile, it is found that the wing cracks propagation paths are almost parallel to the connection line between borehole center and two ends of the preexisting fissure, which indicates that the wing crack propagation path is directly related to the incident direction of the stress wave.

\subsection{The Influence of Fillings and Angles on Total Number $N$ of} Cracks. In Figure 18, the total number $N$ of cracks in the air-filled specimens is almost larger than that in the solifilled and water-filled specimens due to the minimal discontinuity degree of the air-filled specimen. The total number $N$ of cracks in the soli-filled and water-filled specimens is almost close due to the close discontinuity degree of the two kinds of specimens. This indicates the numerical simulation results are in accordance with the experimental results.
In Figure 19, when $L=20 \mathrm{~mm}$ and $40 \mathrm{~mm}$, the total number $N$ increases first and then decreases when the angle increases; when $L=30 \mathrm{~mm}$, the total number $N$ decreases first and then increases; when $L=50 \mathrm{~mm}$, the total number $N$ decreases when the angle increases; when $L=60 \mathrm{~mm}$, the total number $N$ decreases first and then increases when the angle increases, which indicates that blast-induced cracks show a complex phenomenon of mutual restraint under the variables of the fillings, angle $\theta$, and distance $L$.

\subsection{The Far-End Wing Crack Propagation Law}

3.6.1. Analysis on Length of Far-End Wing Crack. In Figure 20 , the length of the far-end wing crack gradually decreases with the increase of the distance $L$. Because of the minimum discontinuity degree in the air-filled specimens, the length of the far-end wing crack is larger than that of the soil-filled and water-filled specimens. Therefore, the law of 


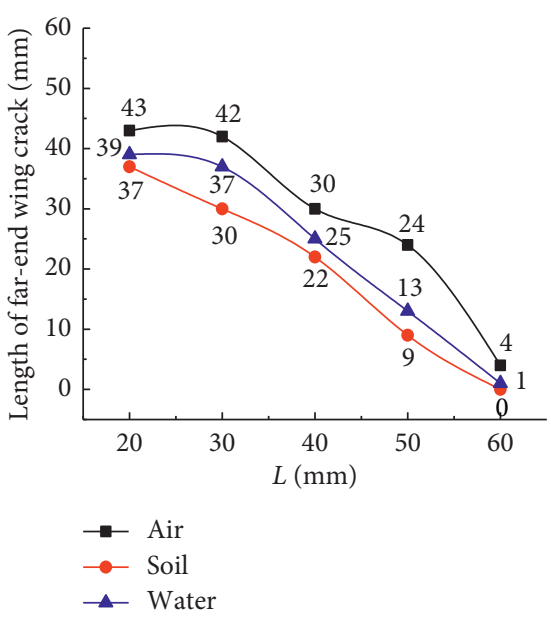

(a)

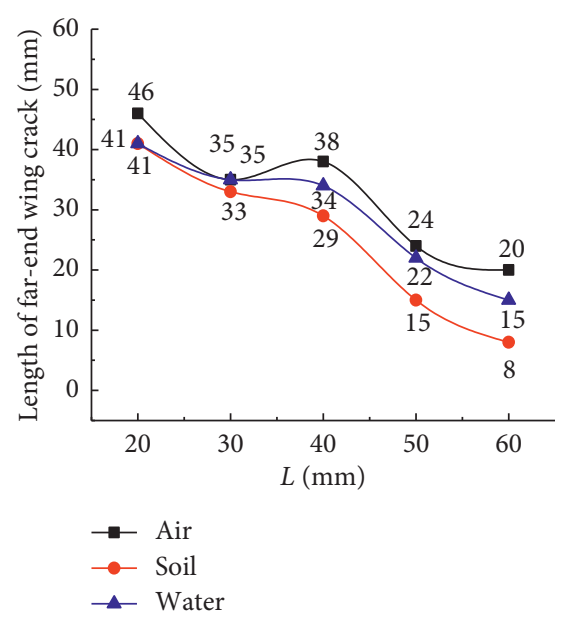

(b)

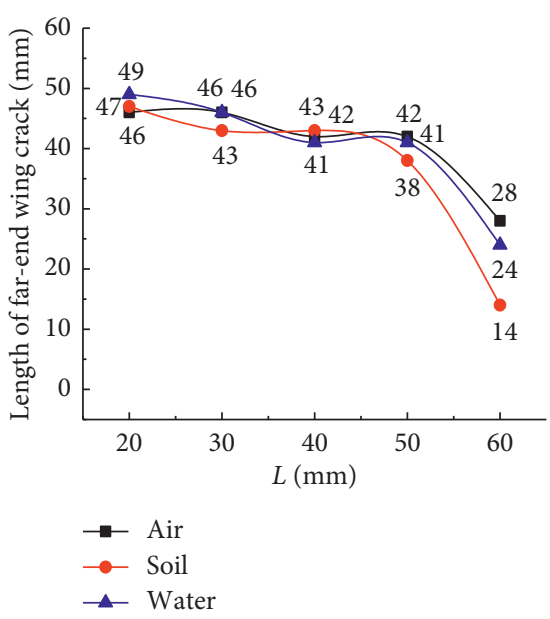

(c)

FIGURE 20: Relationship between fillings and length of far-end wing crack. (a) $\theta=0^{\circ}$; (b) $\theta=45^{\circ}$; (c) $\theta=90^{\circ}$.

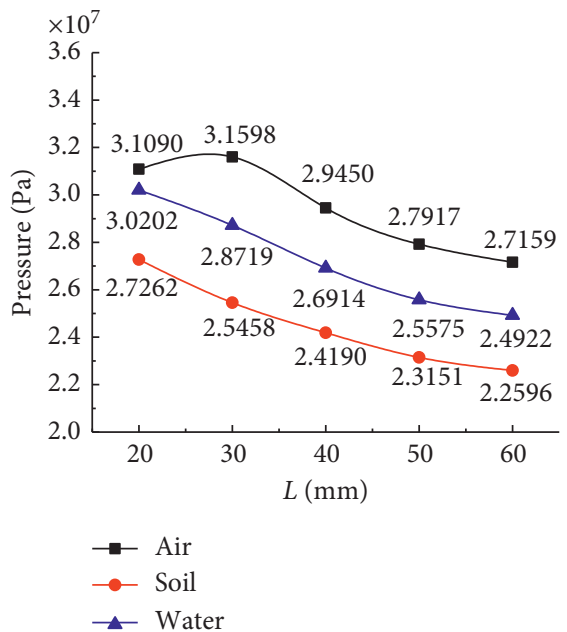

(a)

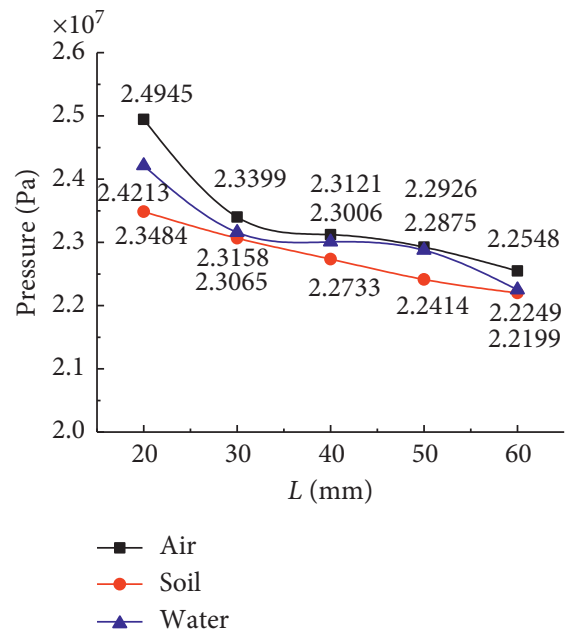

(b)

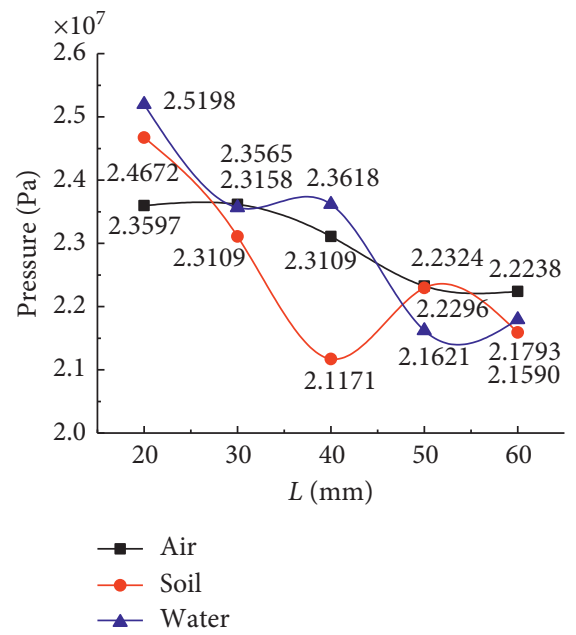

(c)

FIGURE 21: Relationship between fillings and pressure (all pressures are absolute values, but in fact, the pressure values are negative in (b) and (c)). (a) $\theta=0^{\circ}$; (b) $\theta=45^{\circ}$; (c) $\theta=90^{\circ}$.

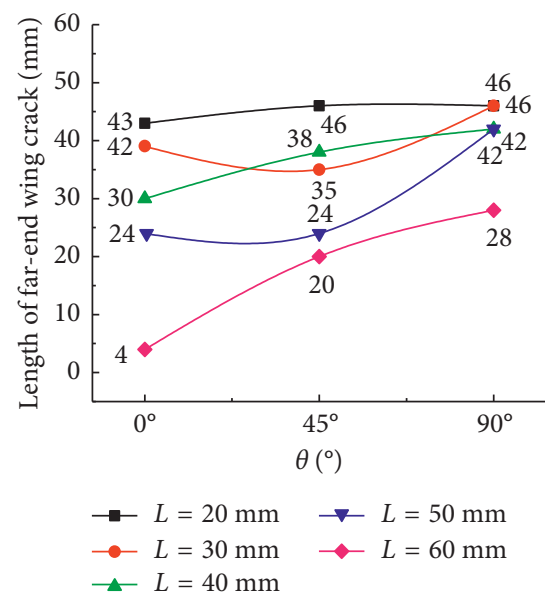

(a)

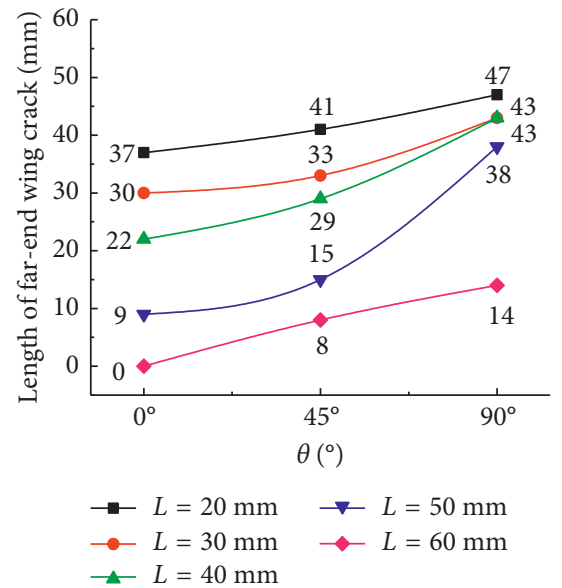

(b)

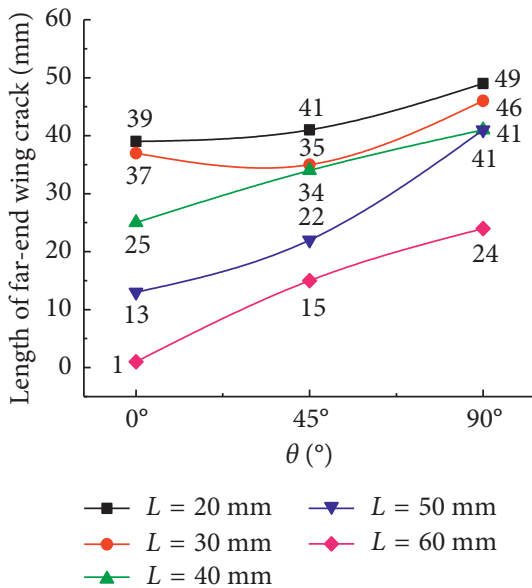

(c)

FIGURE 22: Relationship between $\theta$ and length of the far-end wing crack. (a) Air; (b) soil; (c) water. 


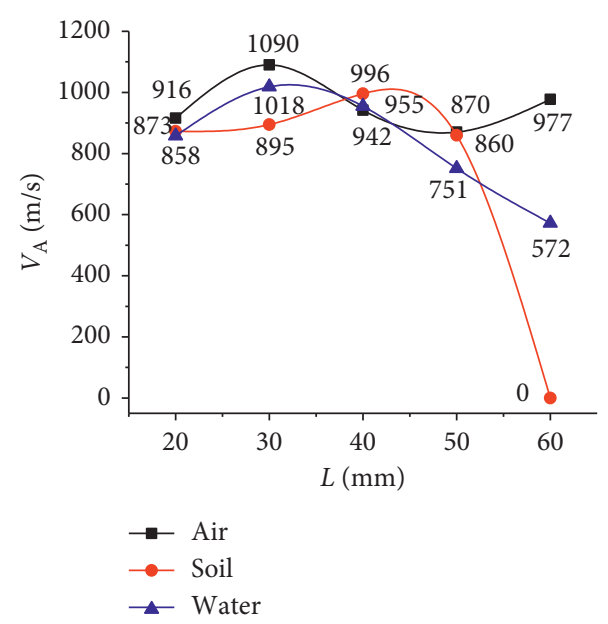

(a)

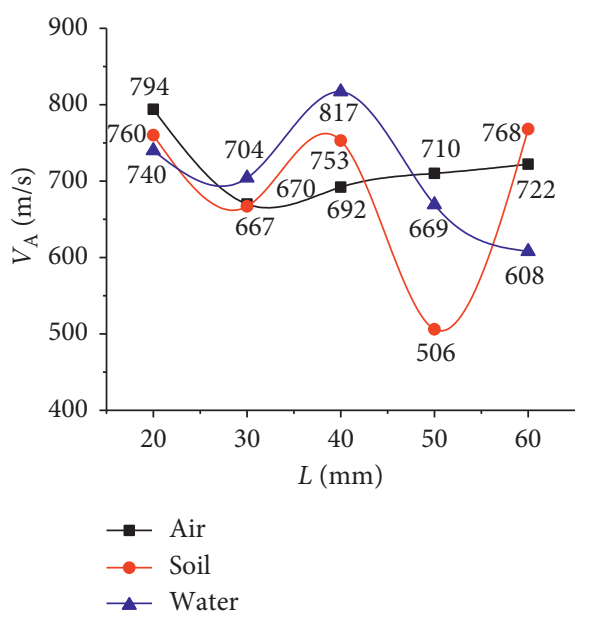

(b)

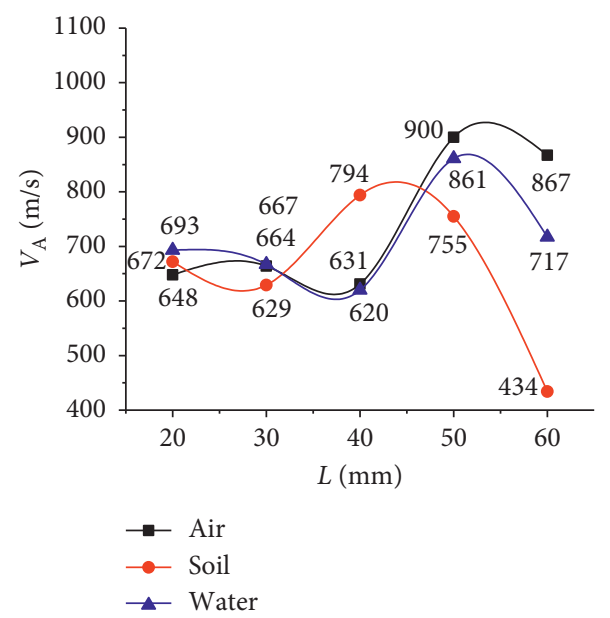

(c)

Figure 23: Relationship between fillings and $V_{\mathrm{A}}$. (a) $\theta=0^{\circ}$; (b) $\theta=45^{\circ}$; (c) $\theta=90^{\circ}$.

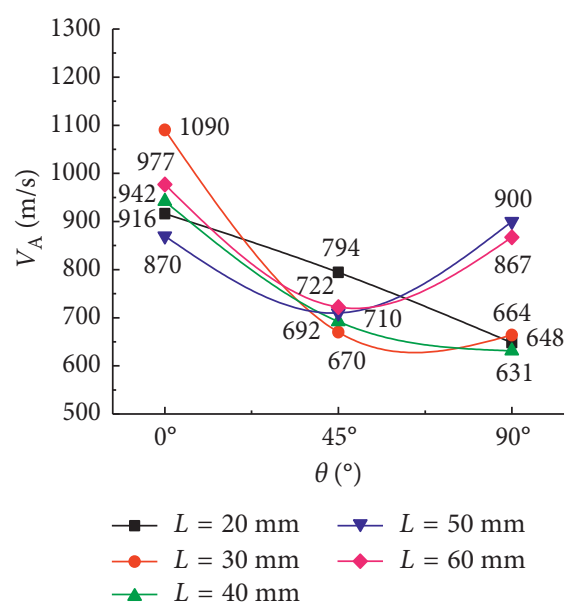

(a)

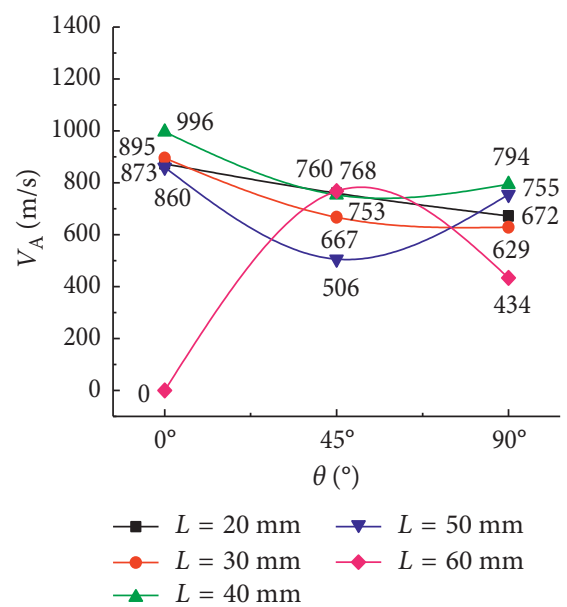

(b)

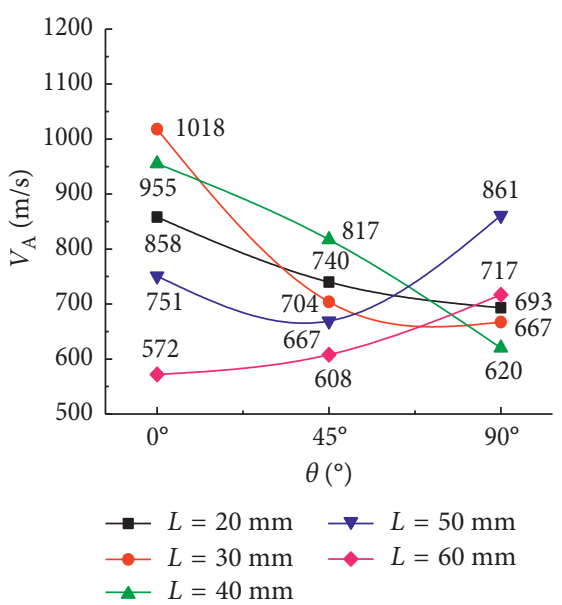

(c)

FIgURe 24: Relationship between $\theta$ and $V_{\mathrm{A}}$. (a) Air; (b) soil; (c) water. 
the far-end wing crack propagation in numerical simulation and physical experiment is more consistent.

It is well known that the reason for the decrease in the far-end wing crack length when the distance $L$ increases is due to the decrease in the explosion pressure at the crack tip. To specify this reason, during the simulation, the peak pressure value at the different distance $L$ is obtained by setting the initiation point of the far-end wing crack as the gauss point, as shown in Figure 21. It can be seen that the peak pressure value of the initiation point does decrease with the increase of the distance $L$, and the peak pressure value of the initiation point of the far-end wing crack in the air-filled specimens is larger than that of the soil-filled and water-filled specimens, which explains the phenomena that the far-end wing crack length increases when the distance $L$ increases; the wing crack length in the air-filled specimens is much larger than that in the soil-filled and water-filled specimens.

In Figure 22, the stress wave energy that travels to the far-end of the preexisting fissure increases when angle $\theta$ increases, and the more energy is obtained when the far-end wing crack initiates, which contributes to the wing crack propagation. Therefore, the length of the far-end wing crack increases as a whole when the angle $\theta$ increases, which is consistent with the experimental results.

3.6.2. Analysis on Average Velocity of the Far-End Wing Crack Propagation. Figure 23 shows the relationship between the average velocity of far-end wing crack propagation $\left(V_{\mathrm{A}}\right)$ and the fillings. The trend of $V_{\mathrm{A}}$ in the air-filled specimen is different at different angles, which is related to the stress of the crack tip caused by fillings and distance $L$. As a whole, the discontinuity degree of soil-filled and water-filled specimens is more similar, and the pressures of the initiation point of the far-end wing crack are close, so the trends of $V_{\mathrm{A}}$ are consistent in the two kinds of specimens.

Figure 24 shows the variation trend of average crack propagation velocity $\left(V_{\mathrm{A}}\right)$ at different angles. In general, with the increase of the angle, $V_{\mathrm{A}}$ of different fillings specimens shows the downtrend; when $\theta=0^{\circ}, V_{\mathrm{A}}$ is larger than that at $\theta=45^{\circ}$ and $90^{\circ}$, which indicates that $\theta=0^{\circ}$ is conducive to crack propagation and the validity of the literature [8]. When $L=20-40 \mathrm{~mm}, V_{\mathrm{A}}$ of the different fillings specimens decreases when the angle $\theta$ increases; when $L=50 \mathrm{~mm}, V_{\mathrm{A}}$ first increases and then decreases when the angle increases, and $V_{\mathrm{A}}$ is inconsistent when $L=60 \mathrm{~mm}$.

\section{Conclusions}

(1) Compared with the experimental results, the numerical simulation can reflect better the entire variation law of blast-induced crack propagation that the total number $N$ of cracks and the length of the far-end wing crack in the air-filled specimen are greater than that in the soil-filled and water-filled specimens.

(2) The wing crack is a kind of mixed mode crack by propagating in the tensile-shear mode. The similar propagation path of the far-end wing crack is related to the direction of the compressive stress wave propagation at the same angle. The length of the farend wing crack in air-filled specimens is larger than that in the soil-filled and water-filled specimens, which shows that the damage range caused by explosion is the largest under this condition.

(3) The damage-time curve of the initiation point of the far-end wing crack presents " $\mathrm{S}$ "-type change, and the damage-pressure curve of the initiation point can fully reflect the law of the dynamic tensile damage evolution process.

(4) The specimen discontinuity degree is measured by the wave impedance difference value between the three fillings and PMMA, and the greater the difference value, the smaller the discontinuity degree and the greater the reflected wave energy. It is generally believed that the larger the angle and the smaller the distance, the greater the reflected wave energy should be in the three kinds of filling specimens, but meanwhile the greater the transmitted stress wave energy also is. So there is a mutual restraint relationship between the distance $L$, angle $\theta$, and fillings types and reflected and transmitted stress wave energy that affects the effect of blast-induced crack propagation. The phenomenon of crack propagation under different fillings can be explained well from the viewpoint of discontinuity degree and stress wave energy, which reveals the general law of blastinduced crack propagation.

\section{Conflicts of Interest}

The authors declare that they have no conflicts of interest.

\section{Acknowledgments}

The authors gratefully acknowledge the support of NSAF (no. U1530140) and the Beijing Institute of Applied Physics and Computational Mathematics through the contract of HG7017105.

\section{References}

[1] Y. Li, Z. Zhu, B. Li, J. Deng, and H. Xie, "Study on the transmission and reflection of stress waves across joints," International Journal of Rock Mechanics and Mining Sciences, vol. 48, no. 3, pp. 364-371, 2011.

[2] L. F. Fan and L. N. Y. Wong, "Stress wave transmission across a filled joint with different loading/unloading behavior," International Journal of Rock Mechanics and Mining Sciences, vol. 60, pp. 227-234, 2013.

[3] X. Huang, S. Qi, A. Williams, Y. Zou, and B. Zheng, "Numerical simulation of stress wave propagating through filled joints by particle model," International Journal of Solids and Structures, vol. 69-70, pp. 23-33, 2015.

[4] J. Song and K. Kim, "Micromechanical modeling of the dynamic fracture process during rock blasting," International Journal of Rock Mechanics and Mining Sciences \& Geomechanics Abstracts, vol. 33, no. 4, pp. 387-394, 1996. 
[5] Z. Zhu, B. Mohanty, and H. Xie, "Numerical investigation of blasting-induced crack initiation and propagation in rocks," International Journal of Rock Mechanics and Mining Sciences, vol. 44, no. 3, pp. 412-424, 2007.

[6] Z. Zhu, H. Xie, and B. Mohanty, "Numerical investigation of blasting-induced damage in cylindrical rocks," International Journal of Rock Mechanics and Mining Sciences, vol. 45, no. 2, pp. 111-121, 2008.

[7] Z. Zhu, "Numerical prediction of crater blasting and bench blasting," International Journal of Rock Mechanics and Mining Sciences, vol. 46, no. 6, pp. 1088-1096, 2009.

[8] G. W. Ma and X. M. An, "Numerical simulation of blastinginduced rock fractures," International Journal of Rock Mechanics and Mining Sciences, vol. 45, no. 6, pp. 966-975, 2008.

[9] M. Bendezu, C. Romanel, and D. Roehl, "Finite element analysis of blast-induced fracture propagation in hard rocks," Computers and Structures, vol. 182, pp. 1-13, 2017.

[10] Z. L. Wang and H. Konietzky, "Modelling of blast-induced fractures in jointed rock masses," Engineering Fracture Mechanics, vol. 76, no. 12, pp. 1945-1955, 2009.

[11] M. Sharafisafa, Z. Aliabadian, R. Alizadeh, and M. Ali, "Distinct element modelling of fracture plan control in continuum and jointed rock mass in presplitting method of surface mining," International Journal of Mining Science and Technology, vol. 24, no. 6, pp. 871-881, 2014.

[12] Z. Wu and L. N. Y. Wong, "Frictional crack initiation and propagation analysis using the numerical manifold method," Computers and Geotechnics, vol. 39, pp. 38-53, 2012.

[13] H. Li and L. N. Y. Wong, "Influence of flaw inclination angle and loading condition on crack initiation and propagation," International Journal of Solids and Structures, vol. 49, no. 18, pp. 2482-2499, 2012.

[14] X. Zhuang, J. Chun, and H. Zhu, "A comparative study on unfilled and filled crack propagation for rock-like brittle material," Theoretical and Applied Fracture Mechanics, vol. 72, pp. 110-120, 2014.

[15] L. Yang, R. Yang, G. Qu, and Y. Zhang, "Caustic study on blast-induced wing crack behaviours in dynamic-static superimposed stress field," International Journal of Mining Science and Technology, vol. 24, no. 4, pp. 417-423, 2014.

[16] R. Hu, Z. Zhu, J. Xie, and D. Xiao, "Numerical study on crack propagation by using softening model under blasting," Advances in Materials Science and Engineering, vol. 2015, Article ID 108580, 9 pages, 2015.

[17] R. Yang, Y. Wang, and C. Ding, "Laboratory study of wave propagation due to explosion in a jointed medium," International Journal of Rock Mechanics and Mining Sciences, vol. 81, pp. 70-78, 2016.

[18] R. Yang, P. Xu, Z. Yue, and C. Chen, "Dynamic fracture analysis of crack-defect interaction for mode I running crack using digital dynamic caustics method," Engineering Fracture Mechanics, vol. 161, pp. 63-75, 2016.

[19] H. P. Rossmanith, A. Daehnke, R. E. K. Nasmillner, N. Kouzniak, M. Ohtsu, and K. Uenishi, "Fracture mechanics applications to drilling and blasting," Fatigue and Fracture of Engineering Materials and Structures, vol. 20, no. 11, pp. 1617-1636, 1997.

[20] D. Rittel and A. Brill, "Dynamic flow and failure of confined polymethylmethacrylate," Journal of the Mechanics and Physics of Solids, vol. 56, no. 4, pp. 1401-1416, 2008.

[21] X. Song, Study on the Stratification Cracking Effect of the Layered Rock Slope Caused by Blasting and Its Influence on the Stability of Layered Slope, Southwest Jiaotong University, Chengdu, China, 2007.
[22] R. Yang, Z. Yue, T.-S. Xiao et al., "Dynamic caustics experiment on crack propagation of jointed medium with controlled blasting," Chinese Journal of Rock Mechanics and Engineering, vol. 27, no. 2, pp. 244-250, 2008.

[23] P. Zhang, Y. Li, X. Wu et al., "Locating system of pipeline inspection gauge based on acoustic detecting," Modern Scientific Instruments, vol. 1, pp. 45-47, 2011.

[24] W. Wang, Experimental Study on the Acoustics Characteristic of Layer Rock and Rock Damage under Explosion Load, China University of Geosciences (Beijing), Beijing, China, 2009.

[25] X. Guo and J. Zhang, Blasting Engineering, China Communications Press, Beijing, China, 2007.

[26] Y. Guo, H. Meng, Y. Qi et al., "Study on mechanisms of the transmission of blasting vibration in the pre-split crack," Chinese Journal of Scientific Instrument, vol. 31, no. 4, pp. 17-20, 2010.

[27] Century Dynamics Inc., AUTODYN Theory Manual, Century Dynamics Inc., Concord, CA, USA, 2003.

[28] Z. Tu and Y. Lu, "Modifications of RHT material model for improved numerical simulation of dynamic response of concrete," International Journal of Impact Engineering, vol. 37, no. 10, pp. 1072-1082, 2010.

[29] N. Murphy, M. Ali, and A. Ivankovic, "Dynamic crack bifurcation in PMMA," Engineering Fracture Mechanics, vol. 73, no. 16, pp. 2569-2587, 2006.

[30] Z. W. Yue, L. Y. Yang, and Y. B. Wang, "Experimental study of crack propagation in polymethyl methacrylate material with double holes under the directional controlled blasting," Fatigue and Fracture of Engineering Materials and Structures, vol. 36, no. 8, pp. 827-833, 2013.

[31] B. Luccioni, D. Ambrosini, G. Nurick, and I. Snyman, "Craters produced by underground explosions," Computers and Structures, vol. 87, no. 21-22, pp. 1366-1373, 20 s09. 


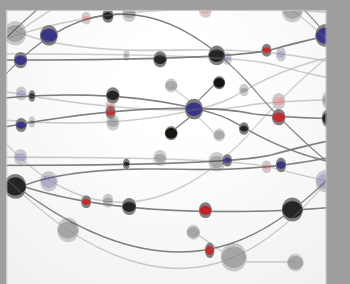

The Scientific World Journal
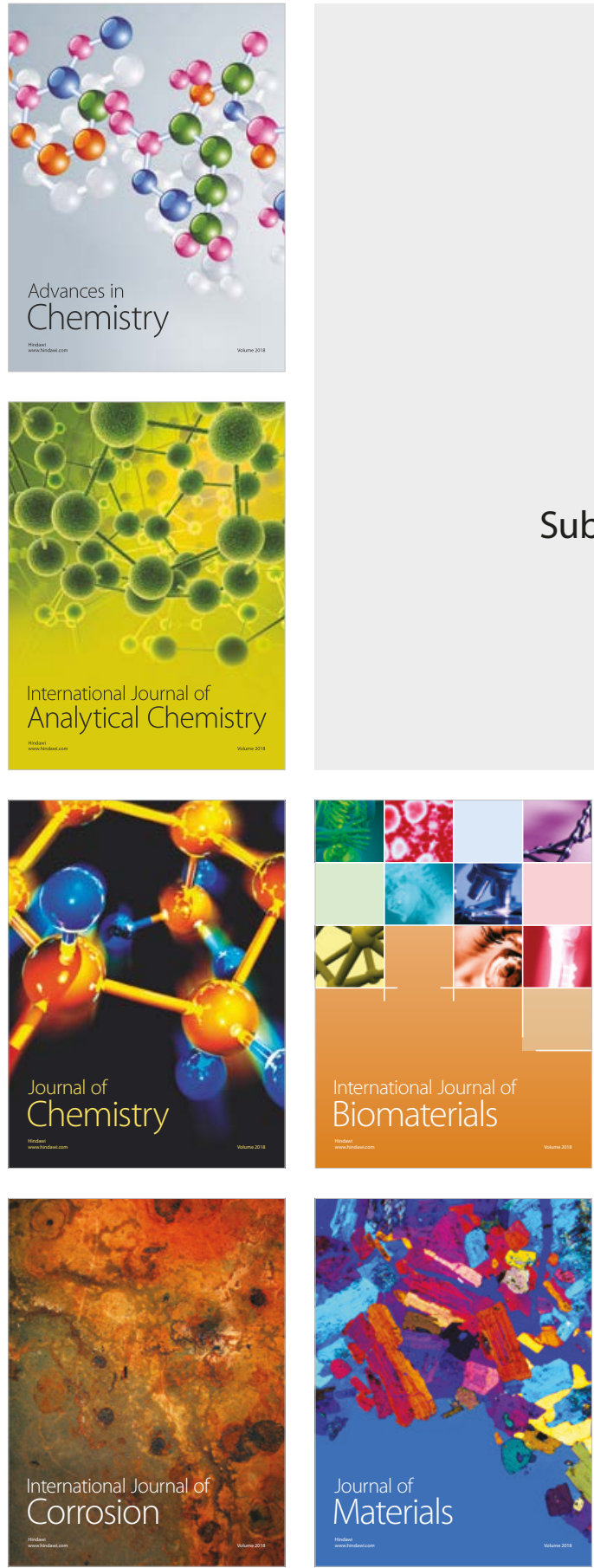

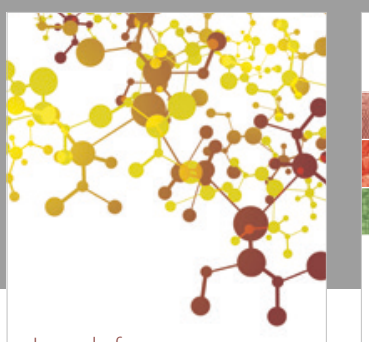

Journal of

Applied Chemistry
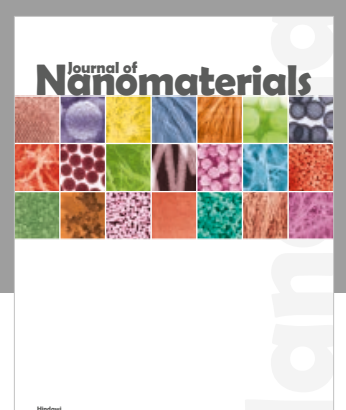

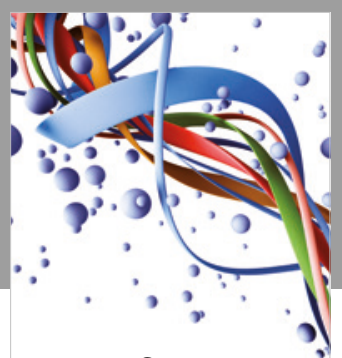

Scientifica

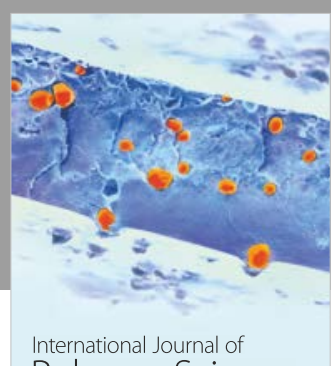

Polymer Science

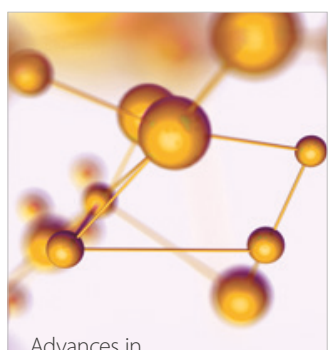

Physical Chemistry
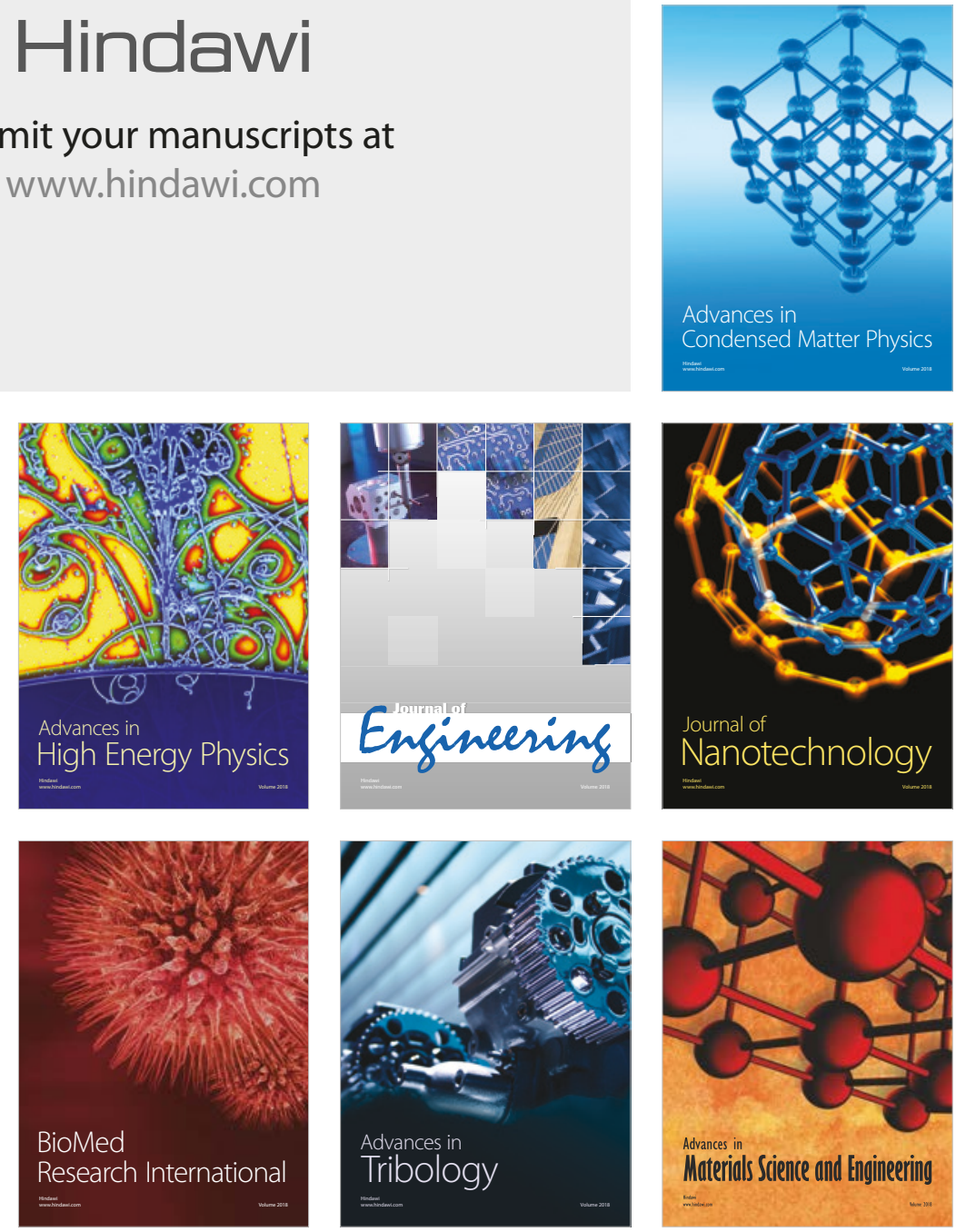